Original paper

\title{
The European Joint Research Project UHDpulse - Metrology for advanced radiotherapy using particle beams with ultra-high pulse dose rates
}

Andreas Schüller ${ }^{\mathrm{a}, *}$, Sophie Heinrich ${ }^{\mathrm{b}}$, Charles Fouillade ${ }^{\mathrm{b}}$, Anna Subiel ${ }^{\mathrm{c}}$, Ludovic De Marzi ${ }^{\mathrm{b}, \mathrm{d}}$, Francesco Romano ${ }^{\mathrm{e}, \mathrm{c}}$, Peter Peier ${ }^{\mathrm{f}}$, Maria Trachsel ${ }^{\mathrm{f}}$, Celeste Fleta ${ }^{\mathrm{g}}$, Rafael Kranzer ${ }^{\mathrm{h}, \mathrm{i}}$, Marco Caresana $^{\mathrm{j}}$, Samuel Salvador ${ }^{\mathrm{k}}$, Simon Busold ${ }^{1}$, Andreas Schönfeld ${ }^{\mathrm{m}}$, Malcolm McEwen ${ }^{\mathrm{n}}$, Faustino Gomez ${ }^{\mathrm{o}}$, Jaroslav Solc ${ }^{\mathrm{p}}$, Claude Bailat ${ }^{\mathrm{q}}$, Vladimir Linhart ${ }^{\mathrm{r}}$, Jan Jakubek ${ }^{\mathrm{r}}$, Jörg Pawelke ${ }^{\mathrm{s}, \mathrm{t}}$, Marco Borghesi ${ }^{\mathrm{u}}$, Ralf-Peter Kapsch ${ }^{\mathrm{a}}$, Adrian Knyziak ${ }^{\mathrm{v}}$, Alberto Boso ${ }^{\mathrm{c}}$, Veronika Olsovcova $^{\mathrm{w}}$, Christian Kottler ${ }^{\mathrm{f}}$, Daniela Poppinga ${ }^{\mathrm{h}}$, Iva Ambrozova ${ }^{\mathrm{x}}$, Claus-Stefan Schmitzer ${ }^{\mathrm{y}}$, Severine Rossomme ${ }^{\mathrm{z}}$, Marie-Catherine Vozenin ${ }^{\mathrm{q}}$

${ }^{a}$ Physikalisch-Technische Bundesanstalt (PTB), Braunschweig, Germany

${ }^{\mathrm{b}}$ Institut Curie, Centre de Recherche, Inserm U 1021-CNRS UMR 3347, Orsay, France

${ }^{\mathrm{c}}$ National Physical Laboratory (NPL), Teddington, United Kingdom

${ }^{\mathrm{d}}$ Institut Curie, Centre de protonthérapie d'Orsay (CPO), Orsay, France

${ }^{\mathrm{e}}$ Istituto Nazionale di Fisica Nucleare (INFN), Sezione di Catania, Catania, Italy

${ }^{\mathrm{f}}$ Eidgenössisches Institut für Metrologie (METAS), Bern-Wabern, Switzerland

${ }^{g}$ Centro Nacional de Microelectrónica (CSIC-CNM), Barcelona, Spain

${ }^{\mathrm{h}}$ PTW-Freiburg, Freiburg, Germany

${ }^{\mathrm{i}}$ University Clinic for Medical Radiation Physics, Medical Campus Pius Hospital, Carl von Ossietzky University Oldenburg, Germany

${ }^{\mathrm{j}}$ Politecnico di Milano (PoliMi), Milano, Italy

${ }^{\mathrm{k}}$ Laboratoire de Physique Corpusculaire de Caen (LPC-CAEN), Normandie Univ, ENSICAEN, UNICAEN, CNRS/IN2P3, 14000 Caen, France

${ }^{1}$ Varian Medical Systems, Troisdorf, Germany

${ }^{\mathrm{m}}$ Sun Nuclear Corp., Melbourne, USA

${ }^{\mathrm{n}}$ Ionizing Radiation Standards, National Research Council of Canada (NRC), Ottawa, Canada

${ }^{\circ}$ Universidad de Santiago de Compostela (USC), Santiago de Compostela, Spain

${ }^{\mathrm{p}}$ Czech Metrology Institute (CMI), Brno, Czech Republic

${ }^{\mathrm{q}}$ Centre Hospitalier Universitaire Vaudois (CHUV), Lausanne, Switzerland

${ }^{\mathrm{r}}$ ADVACAM s.r.o., Praha, Czech Republic

${ }^{s}$ Helmholtz-Zentrum Dresden - Rossendorf (HZDR), Institute of Radiooncology - OncoRay, Dresden, Germany

${ }^{\mathrm{t}}$ National Center for Radiation Research in Oncology (OncoRay), Faculty of Medicine and University Hospital, Technische Universität Dresden, Dresden, Germany

"Queen's University Belfast (QUB), Belfast, United Kingdom

${ }^{v}$ Central Office of Measures (GUM), Ionizing Radiation Laboratory, Warszawa, Poland

${ }^{\mathrm{w}}$ ELI Beamlines, Fyzikalni ustav, Praha, Czech Republic

${ }^{\mathrm{x}}$ Nuclear Physics Institute of the CAS (NPI), Prague, Czech Republic

${ }^{\mathrm{y}}$ EBG MedAustron, Wiener Neustadt, Austria

${ }^{\mathrm{z}}$ IBA Dosimetry, Schwarzenbruck, Germany

\section{A R T I C L E I N F O}

\section{Keywords:}

Dosimetry

FLASH beams

Absorbed dose

Traceability

High dose rates

European metrology project

\begin{abstract}
A B S T R A C T
UHDpulse - Metrology for advanced radiotherapy using particle beams with ultra-high pulse dose rates is a recently started European Joint Research Project with the aim to develop and improve dosimetry standards for FLASH radiotherapy, very high energy electron (VHEE) radiotherapy and laser-driven medical accelerators. This paper gives a short overview about the current state of developments of radiotherapy with FLASH electrons and protons, very high energy electrons as well as laser-driven particles and the related challenges in dosimetry due to the ultra-high dose rate during the short radiation pulses. We summarize the objectives and plans of the UHDpulse project and present the 16 participating partners.
\end{abstract}

\footnotetext{
* Corresponding author.

E-mail address: andreas.schueller@ptb.de (A. Schüller).
} 


\section{Introduction}

Radiation therapy is currently one of the main techniques used for the treatment of cancer. In Europe alone, the number of patients that would have an indication for it at some point during their treatment is predicted to rise by $16 \%$ between 2012 and 2025, reaching 2 million patients treated with radiation therapy (compared to 4 million diagnosed) in 2025 [1]. In external beam radiotherapy, the majority of patients are treated with compact medical electron linear accelerators (LINACs).

Over the last thirty years, major advances in external beam radiation technologies and delivery have significantly improved the 3D conformation of radiation dose to the target volume and reduction of side effects. For example, stereotactic radiotherapy using photon external beam achieves a very steep dose fall-off, enabling very high doses to be prescribed in a single treatment or a few fractions [2]. These kinds of hypofractionated treatments have demonstrated a great potential for improvement of freedom from local failure and even overall survival [3]. However, despite an increasing degree of dose conformity, patients may still experience severe ( $\geqslant$ Grade 3 ) toxicity from radiation treatment, particularly when target volumes overlap organs at risk [4]. In the case of paediatric brain cancers, favourable survival rates have been achieved by treatments including aggressive radiotherapy [5], but often at the cost of severe and irreversible, mostly radio-induced, neurocognitive, endocrine and psychological sequelae [6] with further impairment of quality of life. Even when modern techniques such as intensity-modulated radiotherapy are used, acute radiation reactions in the skin might still arise [7], and be a reason for treatment interruptions, which can negatively affect treatment outcome with radiotherapy. On the other hand, while radioresistant tumours might need higher radiation dose to control local disease progression and local recurrence [8], radiation treatments are, in a number of cases, limited to moderate doses by the risk of intolerable acute [9] or late [10] toxicity. This is especially true when extended radiation fields are required, as for metastases treatment, or in case of highly cellular and infiltrative tumours [11]. Hence, innovative strategies in radiation therapy treatment are still required to widen the therapeutic window, i.e. the range of dose which provides safe effective cure.

FLASH radiotherapy (FLASH-RT) is a promising cancer treatment under development, that involves an almost instantaneous delivery of a high radiation dose in only a few radiation pulses of ultra-high dose rate. It has been reported since the 1960 s that delivering the total dose within only a single nanosecond-pulse of X-rays elicit a sharp increase of cell survival compared to conventional treatment [12]. Such an approach gained a renewed appreciation when it was demonstrated in vivo and with linear accelerators to dramatically reduce adverse side effects to healthy tissues while being as effective for tumour control as conventional radiotherapy (CONV-RT) [13-20]. This so-called FLASH effect would in principle make possible to mitigate dramatically adverse reactions to aggressive radiation therapies even with limited geometrical conformity, and/or to extend the prescribed dose to unprecedented tumour control, as illustrated in Fig. 1.

There is no indication that the sparing effectiveness of FLASH-RT would rest on the type of radiation. The FLASH effect was observed also with photons [18] and protons [21] but the most of the pre-clinical studies investigating the FLASH effect have been conducted so far using electron beams generated by dedicated [22] or modified clinical [23] LINACs with energies not exceeding $20 \mathrm{MeV}$ (for an overview see tables in Refs. $[24,25]$ ). The limited energy of medical electron beams, only suitable for treatment of superficial or shallow tumours, boost treatments and operative scars [26], becomes a significant obstacle for treatment of deep-seated tumours.

The application of very high energy electron (VHEE) [27] beams with energies exceeding $100 \mathrm{MeV}$ could address the limitation of penetration depth and allow a therapeutic dose to be delivered to a deepseated tumour using FLASH regimes but requires huge accelerators for beam production.

The actual accelerator structure of a laser driven electron accelerator is only a few $\mathrm{cm}$ in size and can reach energies up to $\mathrm{GeV}$ [28]. Laserdriven particle accelerators, which are being considered as the next generation of compact and cost-effective accelerators for radiotherapy with VHEE [29] as well as protons [30], can deliver ultra-short radiation pulses of extremely high dose rate (up to $10^{9}-10^{12} \mathrm{~Gy} / \mathrm{s}$ ).

FLASH-RT as well as VHEE and laser-driven beams present significant metrological challenges as there are significantly higher dose rates during each radiation pulse than for radiation pulses from conventional medical accelerators. Fig. 2 illustrates the typical achievable dose per beam pulse and the pulse length at these novel radiotherapy techniques in comparison with the typical beam pulse at conventional (electron/ photon) radiotherapy: A pulse of ultra-high dose from a FLASH electron LINAC (1.5 Gy/pulse [19]) is more than three orders of magnitude intense than a pulse from a conventional medical LINAC ( $1 \mathrm{mGy} / \mathrm{pulse})$, whereby the pulse duration is comparable (few $\mu \mathrm{s}$ ). Similar high dose per pulse is achieved by RF driven VHEE accelerators (2 Gy/pulse [31]) in much shorter pulse duration. Laser driven electrons $(80 \mathrm{mGy} / \mathrm{pulse}$ [32]) or laser driven protons (7 Gy/pulse [33]) are orders of magnitude shorter and therefore have a higher dose rate during the pulse. In an experimental set-up for FLASH protons [34] a pulse is generated by chopping $300 \mathrm{~ms}$ from a continuous beam from a cyclotron. Synchrocyclotrons generate pulsed proton beams. Novel superconducting synchrocyclotrons (IBA S2C2) can reach $1 \mathrm{~Gy} /$ pulse at $10 \mu$ s pulse duration.

The established active detectors for real-time dosimetry as ionization chambers or diodes start to fail when the dose rate/dose-per-pulse is increased beyond what is used in conventional radiotherapy. The red dashed line in Fig. 2 indicates an upper limit, where the ion collection efficiency of a common ionization chamber (Advanced Markus chamber [35]) starts to deviate considerably from unity.

Before implementation in clinical practice, a method to precisely measure radiation doses at these ultra-high pulse dose rates (UHPDR) is required, to ensure reliable delivery of prescribed doses to patients. The project "Metrology for advanced radiotherapy using particle beams with ultra-high pulse dose rates" ('UHDpulse',http://uhdpulse-empir.eu/) will develop a measurement framework, encompassing reference standards traceable to SI units and validated reference methods for dose measurements at ultra-high pulse dose rates. It will also characterise detector systems, develop traceable and validated methods for relative dosimetry, characterise stray radiation, and contribute to codes of

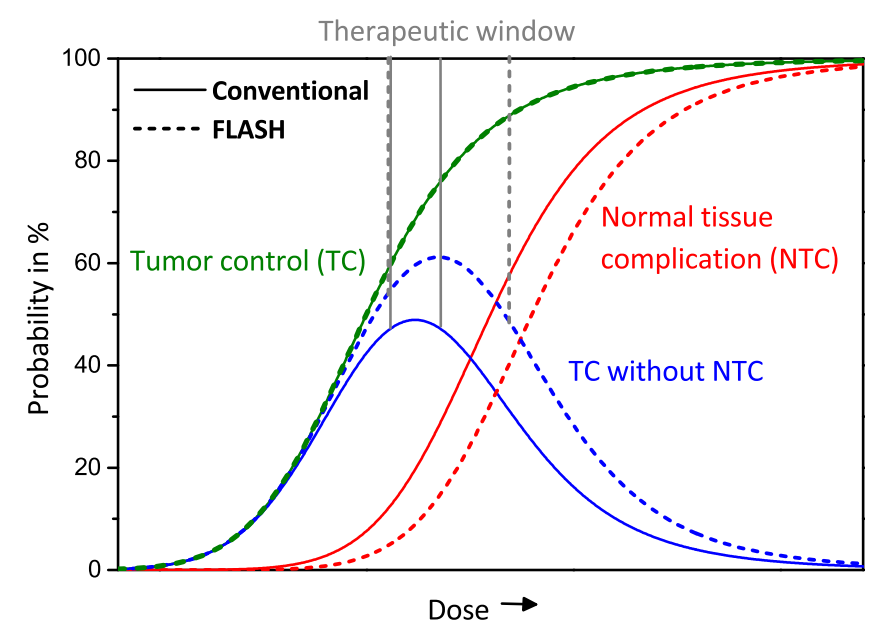

Fig. 1. Illustration of dependence of tumour control probability (TCP, green) and normal tissue complications probability (NTCP, red) on dose for conventional (solid) and FLASH (dashed) radiotherapy. TCP without NTCP (blue) has its maximum in the so-called therapeutic window. (For interpretation of the references to color in this figure legend, the reader is referred to the web version of this article.) 
practice (validated dosimetry formalism). Ultimately, the aim is to insure that patients will receive their prescribed dose, for safer, cost effective, cancer treatments.

UHDpulse is a Joint Research Project in the framework of the European Metrology Programme for Innovation and Research (EMPIR). EMPIR is a metrology-focused programme of coordinated Research and Development which enables European metrology institutes, industrial and other organisations, and academia to collaborate. The UHDpulse project has started in September 2019 with a duration of three years. Interested institutes that want to contribute to the goals of the project may join as a collaborator.

\section{Overview of novel radiotherapy techniques using ultra-high pulse dose rate particle beams}

\subsection{FLASH radiotherapy}

\subsubsection{Electrons}

Ultra-high dose rate biological studies. A large number of in vivo radiobiological experiments recorded significant normal tissue sparing using electron irradiation at ultra-high dose rates, across various species, such as small rodents (mouse [20,37,38,23], rat [39]), developing organisms (zebrafish [16]), and larger mammals (mini-pig and cat [15]), on clinical endpoints (lung fibrosis [37], neurocognitive impairment [38], developmental disorder and deformity [16,39], severe skin reactions $[39,15]$, gastrointestinal syndrome [20,23]). Most importantly, these protocols have shown equally efficient tumour control as CONVRT $[13,20,36]$.

As an illustration of the therapeutic potential FLASH-RT, Fig. 3 shows Normal Tissue Complication Probability (NTCP) and Tumor Control Probability (TCP) after FLASH and CONV-RT in normal brain and brain tumour from Ref [36]. This study demonstrates that the use of FLASH-RT instead of CONV-RT shifts the $50 \%$ - NTCP from $\approx 8$ Gy to $\approx 12.5 \mathrm{~Gy}$ on the mouse model. Then, for example, if a $50 \%$ - probability of toxicity is considered as the acceptable limit, this would allow in this model to increase the dose delivered to the tumor and its close vicinity from less than $30 \%$ of TCP (at 8 Gy) up to $80 \%$-TCP (at $12.5 \mathrm{~Gy}$ ).

Such remarkable pre-clinical results sustain in the long term as the following examples show. Vozenin et al. [15] reported on the FLASH irradiation of the skin of a mini-pig in 2016 (Fig. 4). In this experiment, different spots have been exposed to single shots of irradiation at doses between $22 \mathrm{~Gy}$ and $34 \mathrm{~Gy}$, in FLASH mode (300 Gy/s) $v s$ a conventional dose rate of $5 \mathrm{~Gy} / \mathrm{min}$. The authors reported that nine month post irradiation, the FLASH-irradiated spots (Fig. 5 top) displayed a quasinormal macroscopic and microscopic morphology as well as preserved hair follicles, whereas the conventionally irradiated spots (Fig. 5 bottom) show dramatic fibronecrotic remodelling. Interestingly, after a

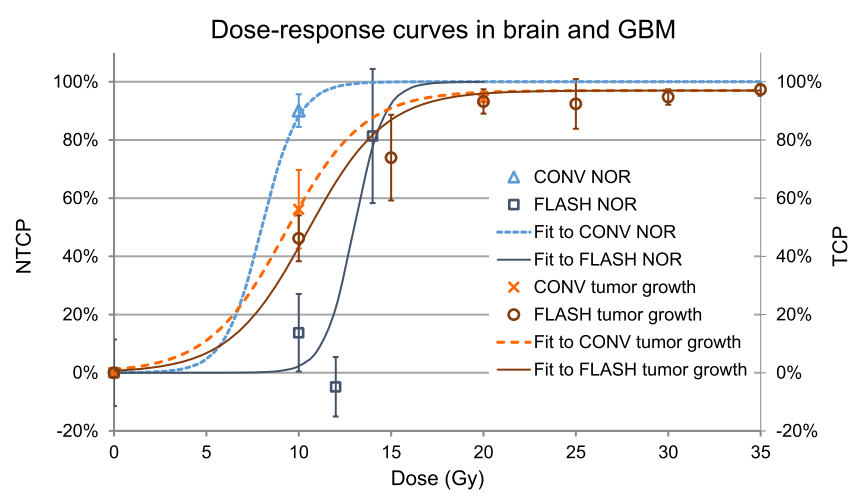

Fig. 3. Normal Tissue Control Probability (NTCP) and Tumor Control Probability (TCP) after FLASH and CONV-RT in normal brain and brain tumour (GBM, Glioblastoma cell line). Normal brain toxicity was investigated using the Novel Object Recognition task (NOR) 2 months post-FLASH and CONV-RT. For details see Bourhis et al. Ref [36].

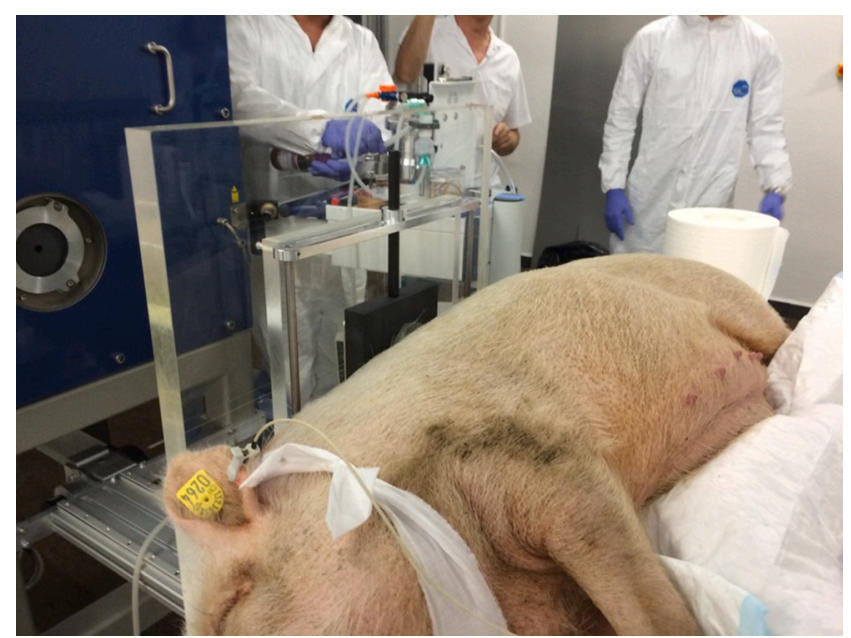

Fig. 4. Mini-pig in front of FLASH electron irradiation facility at Lausanne University Hospital (CHUV) in 2016.

follow-up of 3 years, the skin alteration in the FLASH-irradiated zones is still minimal with a slight hyperkeratosis and depilation, whereas the spots irradiated at conventional dose rates show severe contraction of the skin and deep fibrosis. Fig. 6 shows a photo of the irradiated pig skin taken in late 2019.

Following this experiment, a first human patient was successfully

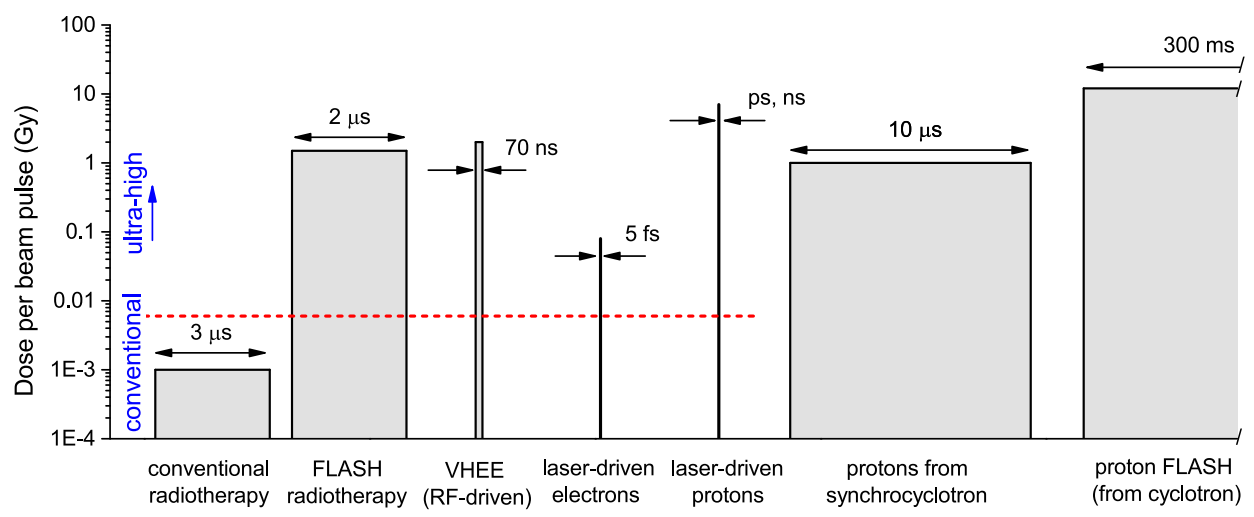

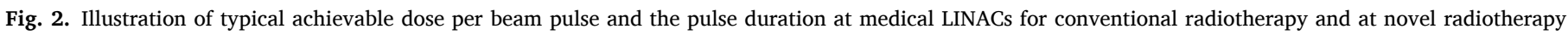

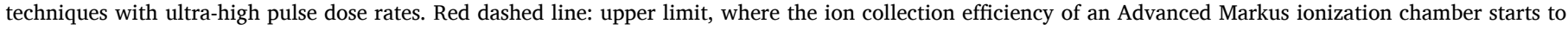
deviate considerably from unity. (For interpretation of the references to color in this figure legend, the reader is referred to the web version of this article.) 


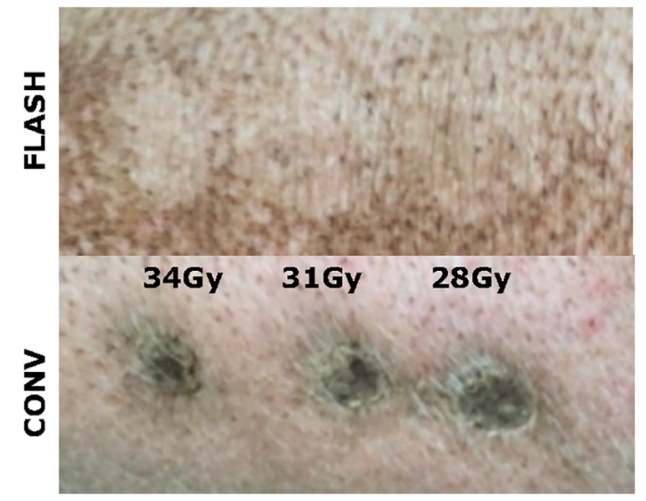

Fig. 5. Mini-pig skin 36 weeks post RT from Ref [15]. The skin of a mini-pig was irradiated in 2016 where same doses were delivered using $300 \mathrm{~Gy} / \mathrm{s}$ (FLASH) and $5 \mathrm{~Gy} / \mathrm{min}$ (CONV). Severe fibronecrotic lesions were observed CONV-irradiated spots whereas the skin in FLASH-irradiated spots presented quasi-normal appearance.

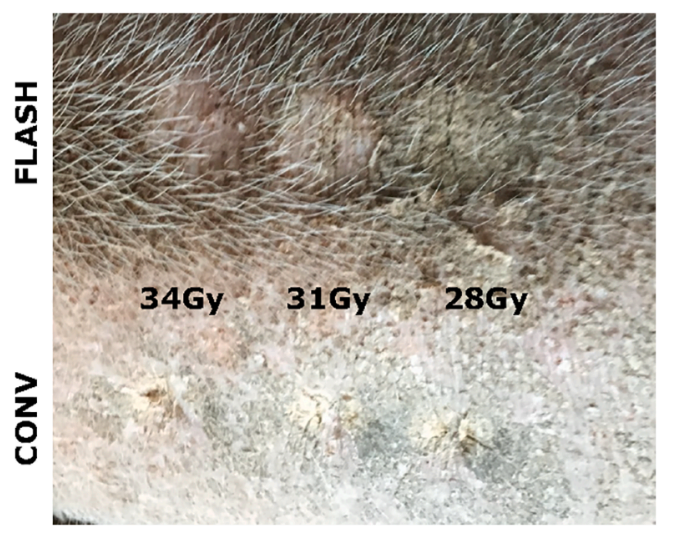

Fig. 6. Long term follow-up of the mini-pig skin 3 years post RT.

treated for recurring cutaneous lymphoma with 15 Gy single dose FLASH-RT (10 pulses of 1.5 Gy within $90 \mu \mathrm{s}$ ), using the same experimental electron LINAC at Lausanne University Hospital [19]. This trial supports the hope that the FLASH effect is clinically applicable.

Electron FLASH-RT implementation. For these studies, both custommade FLASH LINACs [13,22], and specifically modified clinical LINACs [40] were used with an average dose-rate of several dozens of $\mathrm{Gy} / \mathrm{s}$ by increasing the dose-per-pulse to $1 \mathrm{~Gy}$ or more (i.e. a dose-rate $\geqslant$ $10^{6} \mathrm{~Gy} / \mathrm{s}$ in the pulse). However, since an integrate explanation in terms of mechanisms accounting for both normal tissue sparing and tumour control efficiency is still to be deciphered, the minimal requirements in terms of average and/or instantaneous dose-rate to elicit the FLASH effect are not clearly defined yet.

Recently, different physico-chemical models [18,41,42] have been proposed, hypothesizing that the differential impact of FLASH irradiation could be mediated at least in part by total or partial local oxygen depletion under FLASH time scale. This stems from the observation that a doubling of the oxygen concentration in the brain reverses the cognitive protective effects of FLASH-RT in vivo [18], or inversely, that the FLASH effect can only be elicit in physiological oxygen conditions in cultured cells in vitro $[43,44]$.

According to the different models, the impact of these mechanisms would depend either on the tissue's normoxic/hypoxic status or its oxidative damage coping ability, which may explain differential response of tissue to a FLASH pulsed beam. As a matter of fact, some tumors are known to be poorly oxygenated [45] and differential oxidative effect of radiation-induced DNA damage were observed in cancer versus normal cells [46]. These theoretical models, although not experimentally validated to this day to the authors knowledge, suggest that dose-per-pulse or dose-rate in the pulse may be more relevant parameters than the dose-rate averaged on the irradiation duration.

Practically, ultra-high dose rates have been achieved up to $20 \mathrm{MeV}$ on modified clinical accelerators [40], but for now, only by moving closer to the source, which implies quite small homogeneous fields. A promising prospect of clinical implementation of FLASH-RT using electron beams could however be Intraoperative Radiotherapy (IORT), $i$. e. the delivery of radiation to the tumour or the tumour bed while the area is exposed during surgery. IORT is usually performed as a boost for cancers with high risk of recurrence such as cancers of the pancreas, stomach, rectum, and breast, providing a general improvement of local control [47], but also a significant incidence of late normal tissue complications, especially peripheral neuropathy [48]. Modern IORT is achieved with electron LINACs of 6-15 MeV, which makes possible to use the technology of the experimental ultra-high pulse dose rates LINACs $[13,22]$. In addition, IORT is inherently a single-dose therapy, which is similar to the experimental conditions under which the FLASH effect has been observed [16,20,37,38,23].

\subsubsection{Protons}

Ultrahigh dose-rate biological studies. A number of experiments have been recently conducted over a range of dose rates (up to $10^{9} \mathrm{~Gy} / \mathrm{s}$ ) to study the early biological responses of tissues or to validate the occurrence of the FLASH effect with protons. Among them, the possible effects of ultra-high dose rates on cellular response to proton pulses has been investigated using pulses from RF accelerators (up to dose rates of 1500 $\mathrm{Gy} / \mathrm{s}$ ) [49], as well as laser-accelerated protons (up to $10^{9} \mathrm{~Gy} / \mathrm{s}$ ) [50,51]. So far these studies have not shown dose rate dependent effects for a variety of in vitro assays (micronuclei formation, clonogenic survival of cells, DNA double strand breaks detection). These studies employed welloxygenated monolayer and 3D cultures of both cancer and normal cell lines [50-57]. Indications of differences in cellular response between pulsed and continuous irradiation mode or dose-rate dependence have been reported for other effects such as chomosome aberration [58], nitroxidative stress [59], and senescence [49,60]. The biological impact of the temporal aspect of pulsed irradiation has also been investigated with a variable delay between laser-driven bunches ranging from 2 to 60 $\mathrm{s}$, showing that the bunch repetition rate was associated with an oscillation of cell survival $[61,62]$. Recently, zebrafish embryos were treated with proton beams at various doses and dose rates (on the order of 0.08 and $100 \mathrm{~Gy} / \mathrm{s}$ for conventional and FLASH irradiation respectively) using a clinical proton machine [63]. The radiation effect on embryonic survival and the induction of morphological malformations was followed after irradiation and no significant influence of proton dose rate was revealed. For the rate of pericardial edema as acute radiation effect, a significant reduced effect with proton FLASH was however observed for a dose of $23 \mathrm{~Gy}$ [63]. There is also other evidence that large instantaneous dose rate variations (20 Gy/min compared to $40 \mathrm{~Gy} / \mathrm{s}$ ) may play a role in determining the molecular/cellular response of some human lung epithelial cells to proton therapy $[56,64]$. Another recent study using $4.5 \mathrm{MeV}$ protons at $1000 \mathrm{~Gy} / \mathrm{s}$ as compared to $0.05 \mathrm{~Gy} / \mathrm{s}$ also suggested that dose rate had little impact on acute effects, but significantly influenced the expression of long-term radiation-induced inflammatory responses in vitro in normal lung fibroblasts proton [49]. A clinical system with pencil beam scanning was also used to perform whole thorax mice irradiation and compare conventional and FLASH (1 $\mathrm{Gy} / \mathrm{s}$ and $40 \mathrm{~Gy} / \mathrm{s}$ ): a reduced incidence of dermatitis and lung fibrosis was observed at a dose of 17.5 Gy [65], as well as a differential activation of inflammatory/immune, apoptotic and cell cycle genes. Finally, a clinical apparatus able to deliver FLASH proton RT at $94 \mathrm{~Gy} / \mathrm{s}$ using double scattered protons was used to report the first clear proton FLASH RT-mediated normal tissue radioprotection (loss of proliferating cells in intestinal crypts) [21].

Prospective FLASH experimental set-up. In view of the potential clinical 
value of FLASH and the availability of modern clinical proton therapy facilities to achieve this goal, a series of technological developments have been recently investigated by several groups. In Ref. [34], a cyclotron facility used to generate protons at energies between 138 and $198 \mathrm{MeV}$ was modified to produce dose rates exceeding $80 \mathrm{~Gy} / \mathrm{s}$ for a 12 $\times 12 \mathrm{~mm}^{2}$ field size with a scattered beam, thus enabling uniform irradiation for preclinical radiobiology investigations. The quantification of instantaneous dose rates in 3D for different clinical intensitymodulated proton therapy (IMPT) planning strategies and delivery scenarios was investigated [66]. A 'dose-averaged dose rate' metric, locally defined as the dose-weighted mean of the instantaneous dose rates of all spots has been proposed as a criterion for the quantification of the dose rate in complex clinical cases. A mean dose rate $40 \mathrm{~Gy} / \mathrm{s}$ can be achieved with the current machine only for spot-reduced hypofractionated and shoot-through plans. The dose rate distributions and delivery times for lung proton therapy plans was investigated in order to provide a framework for optimising the FLASH characteristics of scanned proton beams. The volumes receiving dose from the beams was determined and the strategies to obtain the shortest delivery time and high dose-rate coverage of healthy tissues was discussed [67].

For modern pencil beam scanning systems, the aforementioned necessary more detailed review on actual beam delivery parameters is especially important, as the influence of spatial beam scanning is not trivially covered by a meaningful "average dose rate". However, today's clinical machines, especially those based on isochronous cyclotrons, are already able to deliver (in non-clinical modes) single pencil beams of high energy protons with average dose rates up to several thousands of Gy/s. As these machines are readily available, they represent a valuable environment for near-future FLASH investigations and potentially quick clinical translation. Beam diagnostic and dosimetry upgrades are a key point here.

\subsection{VHEE radiotherapy}

The possibility of employing VHEE beams for radiation therapy have been proposed back in 2000 by DesRosiers et al. [27]. All previous studies [68-70] have demonstrated several advantages with respect to clinical electron and X-ray beams currently used in radiation therapy. The effective range of those beams, which can be as large as $40 \mathrm{~cm}$ in tissue, makes this modality an excellent candidate for treatment of deepseated tumours in the FLASH regime also with electrons. Moreover, the sharp penumbra and insensitivity to tissue inhomogeneities (in comparison to X-ray and proton beams) [68,71] could enable more controlled delivery of conformal doses to the treated lesions located in the proximity of tissues with varying densities. Bazalova et al. [72] have shown that VHEE radiotherapy could outperform the current state-ofthe-art volumetric modulated arc therapy (VMAT) delivered with Xray beams by comparing 3D dose distributions planned on a patient CT with VMAT and VHEE treatment delivery. This work demonstrated that VHEE RT could offer significant sparing of organs at risk and limit the integral dose delivered to the patient. More recently, Kokurewicz et al. [73], introduced a concept of focusing VHEEs into a patient to optimize dose distribution maps and further reduce surface and exit doses. Currently, there is no clinical machine available for VHEE radiotherapy treatment, however the team of scientists at the SLAC National Accelerator Laboratory is currently developing a pluridirectional high-energy agile scanning electron radiotherapy (PHASER) [74] system, which could become a solution to deliver VHEE therapy in a near future and, possibly, in a FLASH regime. The prototype is still under development. However, it is possible that the first VHEE clinical machine will be available for treatment in the upcoming decade. The increasing interest of the community to employ VHEEs for radiotherapy also stimulated national and international initiatives to establish research facilities (such as CLEAR [75], PRAE [76] and CLARA [77] providing access to VHEE beams in order to accelerate research and development in VHEE domain and enhance faster translation of VHEE RT concepts to clinical practice.

\subsection{Laser-driven beams}

Laser-driven particle acceleration based on the use of intense, ultrashort laser pulses is attracting a very significant research effort. It is emerging as a novel technique for the generation and delivery of beams of energetic particles, particularly in the interest of a potential future driver for radiotherapy for both electrons $[78,79,29]$ and ions $[80,30]$. In particular, novel laser wakefield accelerators enables compact devices [28] to generate VHEE beams, which enables further alternatives for advanced treatment modalities, as already mentioned in the previous section.

Regarding proton and ion acceleration, experiments over the past two decades have shown the production of several tens of MeV proton and ion beams with unique properties, which have stimulated interest in several innovative applications [81]. Proton energies achieved so far are of the order of a hundred $\mathrm{MeV}$ which is within the energy range of use in proton therapy $(60-250 \mathrm{MeV})[82,83]$, and a clear current research aim is to reach the upper end of the range by developing innovative acceleration mechanisms [81], as well as exploiting novel laser facilities currently being developed with increased laser power and intensities [84]. Currently, there are several national and international initiatives for investigating the possible use of laser-driven beams for medical applications: A-SAIL (Advanced Strategies For Accellerating Ions with Lasers) in United Kingdom [80,57]; the ELIMAIA (ELI Multidisciplinary Application of laser-Ion Acceleration) beam line at ELI-Beamlines (Extreme Light Infrastructure) in Czech Republic [85-87], the research at the DRACO and Penelope laser facility at HZDR continuing the onCOOPtics project [88] at OncoRay, the LIGHT collaboration [89,90] and the Munich Centre for Advanced Photonics (MAP) [91] collaboration at the new facility Centre for Advanced Laser Applications [92] in Germany, or the BELLA-i project at LBNL in United States [93]. These studies aim at exploring the potentialities of laser-driven beams towards future therapeutic applications.

The pulse duration of beams from laser-based accelerators, is much shorter than that of conventional RF-based medical accelerators, (typically ps $-\mathrm{ns}$ for protons and fs for electrons compared to $\mu$ s, see Fig. 2) whilst the dose rate during the short pulse is several orders of magnitude higher $\left(10^{9} \mathrm{~Gy} / \mathrm{s}\right)$ than in conventional radiotherapy. The dose per pulse can amount up to several Gy. This implies significant metrological challenges.

\section{Metrological challenges and possible solutions for dosimetry at ultra-high pulse dose rate particle beams}

\subsection{Primary standards}

\subsubsection{Fricke dosimetry in UHPDR electron beams}

The Fricke dosimetry method can be used as primary standard for absorbed dose to water in conventional MeV electron beams [94,95]. For its application in UHPDR electron beams, the dependence of the radiation chemical yield on the parameters relevant for FLASH-RT have to be investigated. The dependence on the pulse dose has been investigated by several research groups for Fricke solutions of different composition [96]. The standard Fricke solution $\left(1 \mathrm{mM} \mathrm{Fe}^{2+}, 0.4 \mathrm{M}\right.$ $\mathrm{H}_{2} \mathrm{SO}_{4}$, air saturated) is nearly independent on the dose rate up to $\approx 2 \mathrm{~Gy}$ per pulse. The radiation chemical yield decreases then by a few percent for $10 \mathrm{~Gy}$ pulses and falls off rapidly for higher dose per pulse [97,98]. The dose-rate independence can be extended to $\approx 20$ Gy per pulse if the $\mathrm{Fe}^{2+}$ concentration is increased by a factor of 10 and if the solution is saturated with pure $\mathrm{O}_{2}$ (super-Fricke solution) $[97,98]$. Sodium chloride may be added to the solution to desensitize the system to organic impurities. However, then the dependence of the radiation chemical yield on the dose per pulse sets in at lower doses [98]. Due to the depletion of oxygen, the radiation chemical yield starts to decrease for a maximal 
dose delivered to the standard Fricke or the super-Fricke solutions of more than $350 \mathrm{~Gy}$ or $1750 \mathrm{~Gy}$, respectively [96]. Another important parameter for ultra-high pulse doses is the pulse repetition frequency. If the temporal spacing between the pulses is too short (sub ms), the reduction of the radiation chemical yield due to radical-radical reactions has to be studied more closely. However, so far no systematic investigation of this parameter has been performed. The existing results of carried out experiments for the application of Fricke dosimetry in ultra-high dose pulses are promising. However, extended studies with FLASH parameters are needed before the Fricke dosimetry can be used as primary standard in UHPDR electron beams. Such studies will be carried out by as part of work package 1 (WP 1) of UHDpulse.

\subsubsection{Graphite calorimeter for UHPDR proton beams}

Graphite calorimeters have been well established as primary standard level instruments for dosimetry in conventional radiotherapy $[99,100]$. For proton and ion therapy, NPL is commissioning the first primary standard based on a graphite calorimeter, performing a comprehensive program of experimental campaigns in clinical hadron therapy facilities in UK and Europe. NPL has considerable expertise in graphite calorimetry and the use of graphite calorimeters for proton and ion beams has been already demonstrated [101,102]. The NPL new graphite calorimeter, which is intended to be used as a primary standard of absorbed dose to water for clinical proton beams, is robust and portable enough to be used directly in the end-user facility. The aim is to achieve an uncertainty on reference dosimetry for protons of around $2 \%$ (at 95\% confidence level) [103], which is approximately half the estimated uncertainty for calibrations based on IAEA TRS-398 [104]. However, the application of graphite calorimeters in proton beams with ultra-high pulse dose rates is not trivial and has not yet been explored. Therefore, to allow for established and traceable dosimetry, an investigation (and possible optimisation) of graphite calorimeters in particle beams with ultra-high dose per pulse and with ultra-short pulse duration is being carried out in the framework of the UHDpulse project. Moreover, the development of graphite calorimeters for absolute dosimetry for ultra-short, UHPDR charged particle beams from laser-driven accelerators is also planned in the project in WP 1.

FLASH proton beams. Graphite calorimetry has never been explored for UHPDR protons, therefore, challenges related to the possible influence of the substantial instantaneous heating on the calorimeter response must be properly investigated. NPL has recently conducted an experimental campaign at the Cincinnati's Children Proton Therapy Centre in United States, where traceability to the NPL portable graphite primary standard has been provided in order to give confidence in interpretation of further pre-clinical FLASH measurements carried out at this Centre [105]. Moreover, ion recombination measurements with the PTW Advanced Markus and Roos and IBA PPC05 ionization chambers have been carried out. Dose rates ranging from conventional up to those used typically to achieve the FLASH effect have been explored (approx. $1-140 \mathrm{~Gy} / \mathrm{s})$.

Furthermore, in the framework of UHDpulse an experimental campaign at the FLASH setup [34] of the Proton Therapy Center of the Institute Curie in Orsay (CPO) is planned with the aim of providing traceability to the NPL primary standard up to ultra-high dose rates and investigating ion recombination in ionization chambers under such conditions. Moreover, during the same experiment, a prototype of small portable graphite calorimeter (SPGC, see Fig. 7), developed by NPL on the basis of a previous prototype used for low energy proton beams [101], will be tested and the response will be compared against primary standard graphite calorimeter. The SPGC is intended to be used for absolute dosimetry of laser-driven proton beams. The possibility to reproduce at the $\mathrm{CPO}$ a sharp temperature rise, similar to what is expected for a laser-driven beam and, at the same time, dealing with very well controlled and reproducible beams will allow for a systematic characterization of the SPGC.

Laser-driven proton beams. Laser-driven beams are characterized by

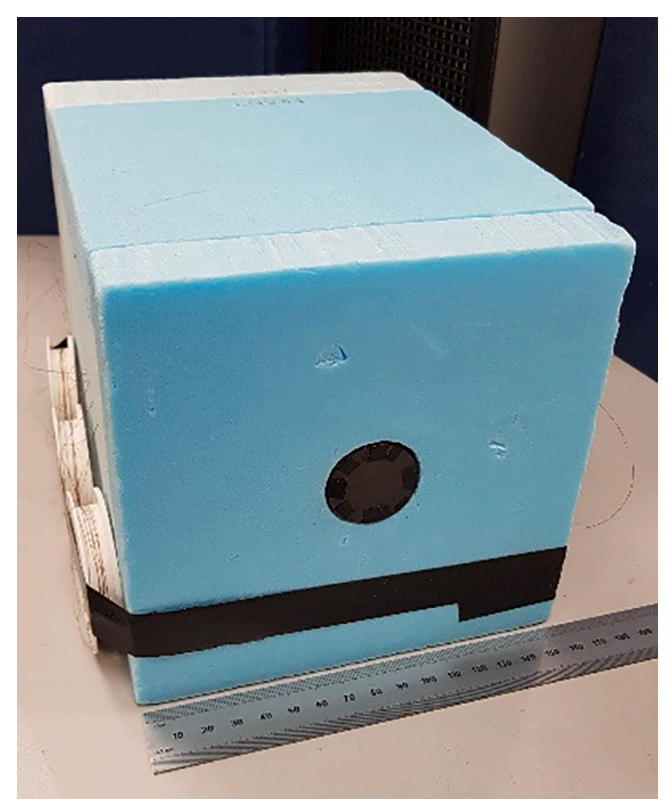

Fig. 7. The NPL small portable graphite calorimeter (SPGC) with the $15 \mathrm{~cm}$ side Styrofoam enclosure, with the circular jacket visible at the surface (in black).

extremely short pulses (ps - ns for protons) and high doses per each single pulse (up to several Gy), therefore producing dose rates in the pulse several order of magnitudes higher with respect to protons and ions accelerated by conventional RF machines. Dosimetry at these ultrahigh dose rates is even more challenging than for FLASH proton beams produced by RF accelerators. The harsh experimental environment typical of high-power laser accelerators as well as the presence of large electromagnetic pulses (EMP) further complicate dose measurements with active dosimeters.

Approaches employed so far for the dosimetric characterization of laser-driven protons include the use of Faraday cups for absolute dosimetry $[106,86]$, transmission ionization chambers [61] as well as passive detectors such as radiochromic films (Gafchromic EBT2 or EBT3), previously calibrated with beams generated by RF accelerators (see $[107,108]$ ). For a broader review of the diagnostic techniques employed for characterizing and monitoring laser-driven proton beams we refer the reader to Ref. [109].

The challenge of providing reliable dose measurements for laserdriven ions will be addressed in the framework of the UHDpulse project by developing, optimizing and characterizing new dosimtetric approaches based on the use of small graphite calorimeters. In particular, a new approach has been proposed for dosimetry of laser-driven protons, never exploited so far, which consists on the measurement of the absorbed dose using a prototype of the SPGC (Fig. 7). The SPGC has been operated for the first time in the ultra-high dose-rate laser driven proton beam produced by the PW Vulcan Laser at the Rutherford Appleton Laboratory in the UK. Doses between 1-3 Gy per pulse were produced. Despite the presence of harsh experimental environment and large EMPs, a very good signal-to-noise ratio was achieved with the SPGC, demonstrating the feasibility of calorimetry measurements in a laser environment [110]. Further experimental campaigns with laser-driven proton beams are planned in the framework of UHDpulse at HZDR in Dresden (Germany) and at the ELIMAIA facility of Eli-Beamlines in Prague (Czech Republic).

\subsubsection{Graphite calorimeter as reference for dosimetry of VHEE beams}

Prior to the translation of VHEE studies into the clinical stage it is essential to develop accurate dosimetry protocols and characterize suitable detectors that could serve as secondary standard dosimeters for 
this radiotherapy regime. The UHDpulse project will address this by investigating a number of commercially available ionization chambers and their optimal operational parameters for VHEE dosimetry. The assessment of the ion chamber performance will be conducted against absolute dose measurements carried out with a graphite calorimeter. The experimental setup is shown in Fig. 8.

Using this approach, it has been recently reported by McManus et al. [111] that the PTW Roos chamber, routinely used in clinical electron beam dosimetry, is suffering from very large ion recombination effects in ultra-short pulsed high dose-rate VHEE beams. These effects cannot be corrected using neither two-voltage analysis (TVA) method nor applying any of the available analytical modes previously developed by Boag [112,113] or DiMartino [114].

\subsubsection{Graphite calorimeter for UHPDR electron beams}

The Central Office of Measures (GUM) has developed three different designs of durable and portable graphite calorimeters with a view to using them as a primary standards of the absorbed dose to water for high energy photons, electrons and proton beams. Within the UHDpulse project GUM will perform Monte Carlo simulations to determine correction factors to adapt one of the constructions - the portable graphite calorimeter IGNAS-GC16-002 (see Fig. 9) - for UHPDR electron beams. The next step will be the validation of this calorimeter by means of NPL's primary standard graphite calorimeter. GUM, with guidance from NPL, will perform a series of measurements with its portable graphite calorimeter in a reference field for conventional radiation at NPL. The final step will be an investigation of GUM's calorimeter in the UHPDR electron beam available at PTB in order to find a consistent procedure of operation under such conditions. GUM will determine correction factors for the heat transport in the calorimeter in UHPDR electron fields using finite element method (FEM) calculations. Aim is a direct validation of the beam by means of a further primary standard measuring device. Results and uncertainties will be compared with PTB's and METAS' primary standards.

\subsubsection{Al calorimeter for UHPDR electron beams}

In developing primary absorbed dose standards for UHPDR beams it is important to investigate possible systematic effects and/or ensure that standards developed by different groups are not strongly correlated. To that end, a transportable aluminium calorimeter that had been developed at the National Research Council Canada (NRC) originally for the measurement of the dosimetry parameter $\mathrm{W}_{\text {air }}$ [115] was tested in a UHPDR electron beam at PTB. The calorimeter is an open-to-atmosphere design but, in contrast to the more common graphite calorimeters used in a number of primary standards laboratories, the specific calorimeter

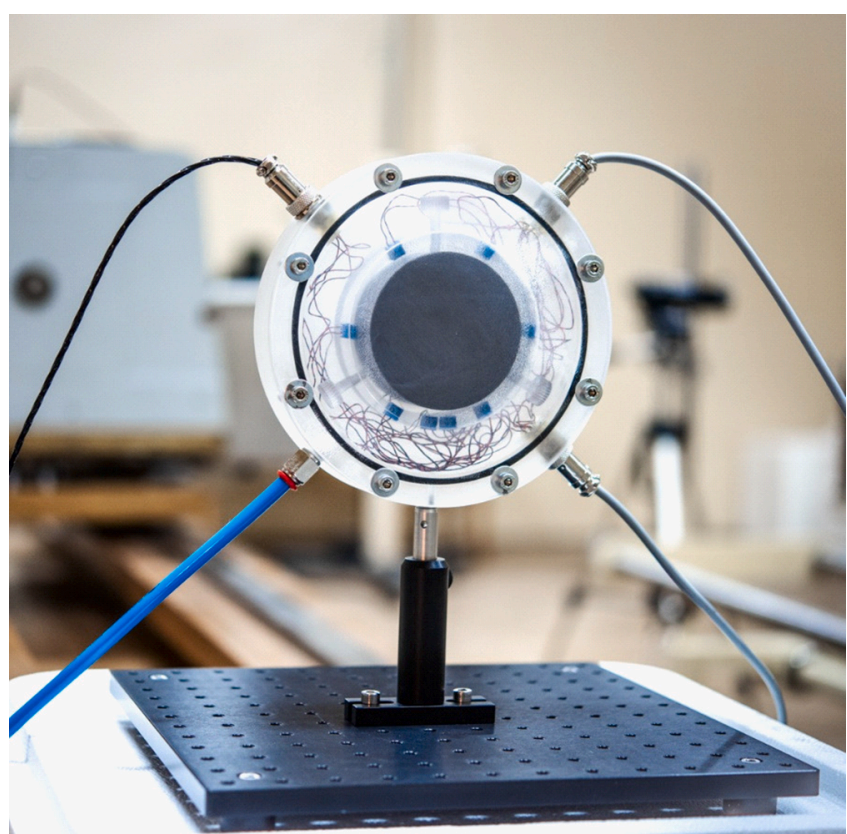

Fig. 9. GUM's portable graphite calorimeter to be tested for use as a primary standard for UHPDR electron beams.

employed here uses aluminum as the absorber material. This was chosen because a number of previous investigations had indicated that the granular nature of bulk graphite leads to inhomogeneities and impurities that can be difficult to quantify. Aluminum, in contrast, is obtainable in a very pure, highly homogenous form. The calorimeter was tested in a UHPDR electron beam in the range of 0.3 to $1.8 \mathrm{~Gy} / \mathrm{pulse}$. The relative dose delivered was determined using a beam current transformer as monitor that measures precisely the total charge of each electron beam pulse prior to exiting the accelerator. Fig. 10 shows the Al-calorimeter response as a function of the charge per beam pulse, i.e. as a function of the dose per beam pulse.

An analysis of the signal-to-noise indicated that single pulses could be measured at all dose-per-pulse values in the examined range without compromising the overall accuracy of the dose determination. The calorimeter showed good reproducibility, with a typical standard deviation of the normalized temperature rise of $0.1 \%$. The deviation of the Al-calorimeter response from the linear fit function shown in Fig. 10 was generally smaller than $0.5 \%$.

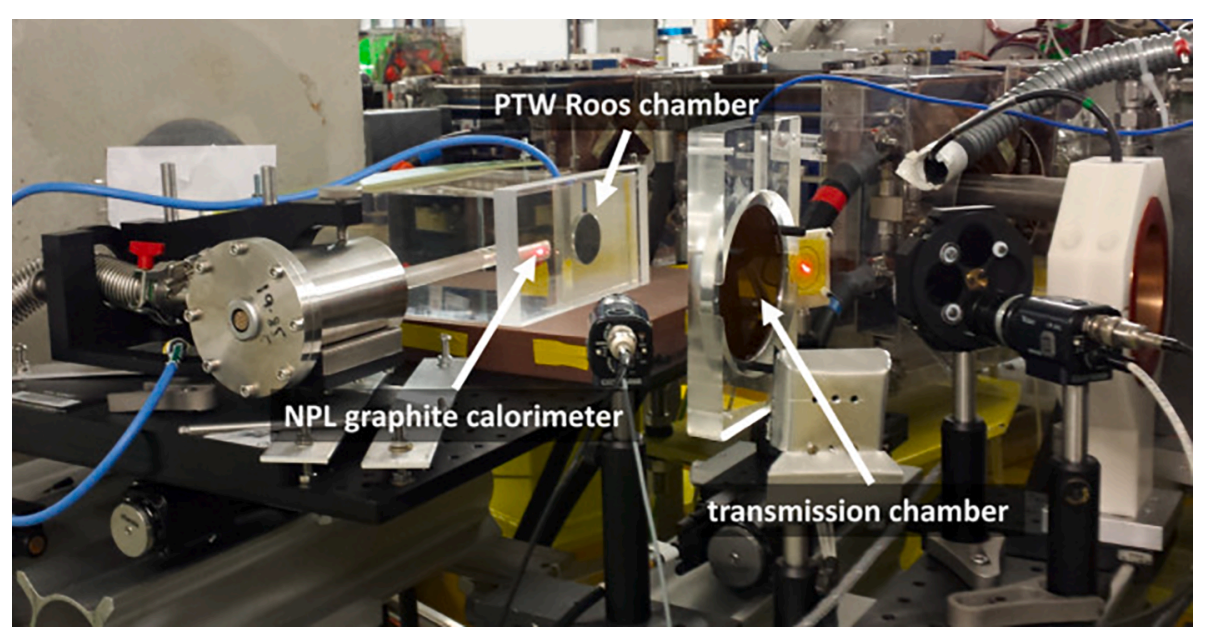

Fig. 8. The experimental setup of VHEE dosimetry study at CLEAR facility [75] with the NPL graphite calorimeter, ion chamber and monitor chamber placed along the beam line with the beam travelling from right to left. 


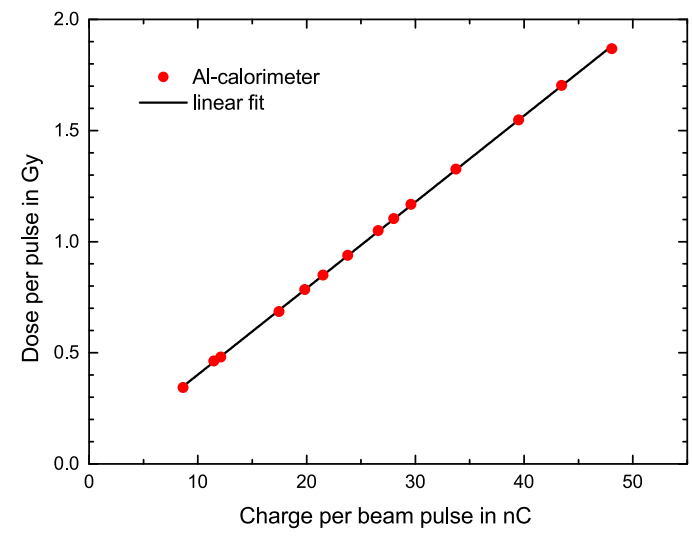

Fig. 10. Dose per pulse from Al-calorimeter measurements as a function of the charge per beam pulse measured by a beam current transformer. Line: linear fit.

This initial measurement demonstrates that a calorimeter could be suitable as real-time detector for the accurate dosimetry of electron beams with ultra-high dose per pulse. The simplicity of the calorimeter design together with the transportability means that it could potentially be used in a clinical setting. This possibility will be investigated within the framework of UHDpulse.

\subsection{Secondary standards and relative dosimetry}

\subsubsection{Ionization chambers}

The challenges of electron beam dosimetry. The international codes of practice for pulsed high-energy electron-beam dosimetry [104] recommend the use of plane parallel ionization chambers for the measurement of the absorbed dose, with a correction of the ionization chamber response for the lack of complete charge collection due to ion recombination using "two-voltage analysis" (TVA) method. However, it is known that the standard TVA starts to fail when applied to beams with high dose per pulse, as in IORT beams (20-120 mGy/pulse), because the non-inclusion of free-electron effects substantially exaggerate the correction to apply [114]. At ultra-high dose per pulse ( $>$ few hundred $\mathrm{mGy} / \mathrm{pulse}$ ), the ion concentration created by the pulse in the chamber cavity enhanced even more significantly the general recombination, causing a sharp decrease of the ion collection efficiency from $0.1-1 \mathrm{~Gy} /$ pulse, with values typically below $50 \%$ for dose-per-pulse $>1 \mathrm{~Gy} /$ pluse [35]. For ultra-high dose rates also the screening of the chamber electric field can contribute significantly to enhance the general recombination effects. To date, a universally accepted model of ion recombination within this range of dose-per-pulse is still lacking and it would most probably require a reference dosimeter with a response independent of dose rate.

As a result, absolute dosimetry on FLASH beams is currently mainly performed with chemical and passive dosimeters, such as radiochromic films, alanine or thermo-luminescent dosimeters, whose responses are believed to be constant when passing from low- to high-dose-per-pulse beams [116]. Regrettably, even with the most careful handling, they have been found to agree within $3 \%$, and their respective relative standard uncertainties are about $3 \%$, which is not low enough for clinical use. Passive dosimeters have also the drawback to make impossible direct reading, i.e. the determination of an accurate dose needs hours or even days.

The challenges of proton beam dosimetry. Today, most proton therapy institutions implement reference dosimetry using ionisation chamber based techniques to measure the absolute absorbed dose per monitor unit, under simple and reproducible conditions in a water phantom [117] and correction factors for the reduced ion collection efficiency due to recombination are applied to the ionisation measurements. The IAEA TRS-398 [104] code of practice describes thoroughly these corrections for high energy photon and electron beams, but remains less precise for proton beams. Indeed, the recommendations of this code concern mainly the approach of pulsed proton beams, but it is recognised that the conditions for this approach are not systematically met in clinical proton beam dosimetry due to the high pulse repetition frequency of current beams (e.g around $100 \mathrm{MHz}$ for a cyclotron accelerator, which sometimes should be treated as continuous) [118]. In addition, volume recombination can be very much affected by the dose rate, dose per pulse and the primary particle flux, and the validity of current methods must be questioned in view of the limited experimental data available in FLASH conditions with dose per pulse values well above those used in routine clinical proton therapy.

Possible solutions. The use of air ionization chambers in the ultra-high dose per pulse regime exhibit serious drawbacks due to the presence of a limited charge collection efficiency that can yield ion recombination correction factors that depart significantly from unity. There has been many efforts to provide an underlying model describing those effects $[113,114]$ while most of the current approaches are phenomenological [35] with parameters that do not have a proper physical meaning. Currently Boag-type models present large discrepancies to describe the ion recombination in the high and ultra-high dose per pulse beam conditions [31]. Alternatively the description of the associated non-linear effects can be also performed through numerical solutions [119] of the non-linear coupled differential equations associated to the chargecarrier densities in the chamber. For example, for a plane parallel ionization chamber the unidimensional equivalent equations would be:

$$
\begin{aligned}
\frac{\partial n_{+}(x, t)}{\partial t}= & N(x, t)-\alpha n_{+}(x, t) n_{-}(x, t)-\theta n_{+}(x, t) n_{e}(x, t) \\
& -\frac{\partial}{\partial x}\left\{E(x, t) \mu_{+} n_{+}(x, t)\right\} \\
\frac{\partial n_{-}(x, t)}{\partial t}= & \gamma n_{e}(x, t)-\alpha n_{+}(x, t) n_{-}(x, t) \\
& +\frac{\partial}{\partial x}\left\{E(x, t) \mu_{-} n_{-}(x, t)\right\} \\
\frac{\partial n_{e}(x, t)}{\partial t}= & N(x, t)-\gamma n_{e}(x, t)-\theta n_{+}(x, t) n_{e}(x, t) \\
& +\frac{\partial}{\partial x}\left\{w_{e} n_{e}(x, t)\right\}
\end{aligned}
$$

where $E(x, t)$ stands for the electric field, $N(x, t)$ corresponds to the number of electron-ion pairs released per unit time and volume due to ionization and $n_{+}(x, t), n_{-}(x, t)$ and $n_{e}(x, t)$ are the positive ion, negative ion and electron densities in the chamber, $\alpha$ and $\theta$ are the ion-to-ion and electron-to-ion recombination constants, $\mu_{+}, \mu_{-}$are the positive and negative ion mobilities, $\gamma$ is the electron attachment constant and $w_{e}$ is the electron drift speed.

Even these detailed numerical models are an overall description of the actual charge carriers and their transport in the chamber given the complexity of the different ion species formed in air [120]. The most straight-forward strategy for this ionometric dosimetry is the use of small gap chambers that provide the enhancement of the free-electron component with higher mobility than the ions produced in air, smaller carrier densities in the gap and thus a reduced recombination effect. While most of the commercially available chambers have distance between electrodes in excess of $0.5 \mathrm{~mm}$, it could be possible to extend the use of air ionization chambers as a secondary standard to high and ultrahigh dose per pulse range if the air gap is reduced as shown in Fig. 11. The ion recombination correction factor from Fig. 11 has been obtained through numerical solution of the Eqs. (1) for a $5 \mathrm{~Gy} /$ pulse FLASH pulse with a $1 \mu$ s duration as a function of the air gap in a plane parallel chamber geometry operated at $300 \mathrm{~V}$. If the ion recombination correction factor is close to unity so that its uncertainty hardly contributes, then ionization chambers could be used as a secondary standard also for UHPDR beams.

Within UHDpulse, work on a better theoretical model of ion 


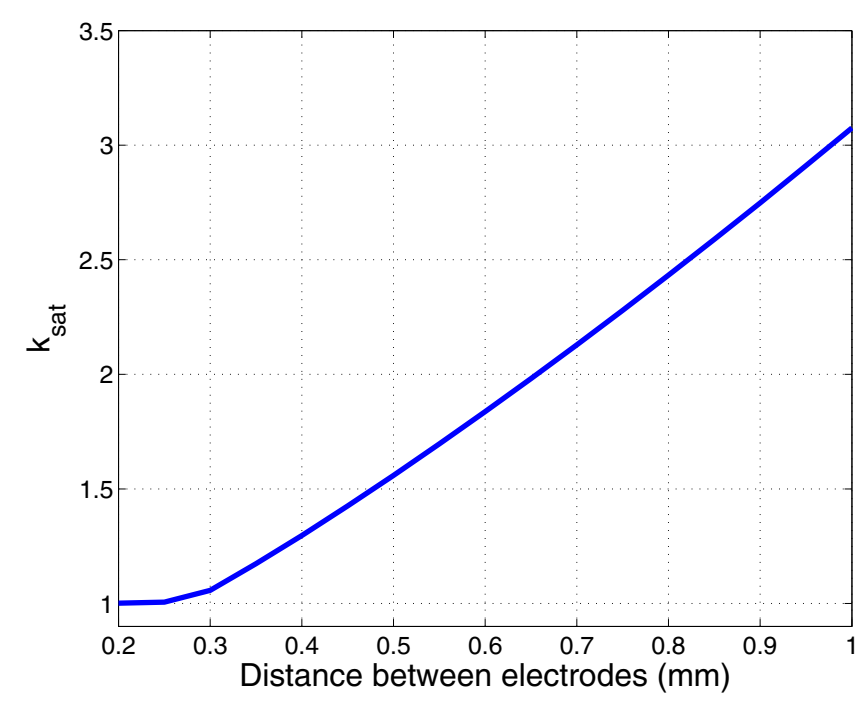

Fig. 11. Simulated ion recombination correction factor for a plane parallel air ionization chamber operated at $300 \mathrm{~V}$ as a function of the distance between electrodes for a pulse of 5 Gy with a $1 \mu$ s duration.

recombination is being carried out and new ionization chamber prototypes with small electrode spacings are being developed and tested in UHPDR beams.

\subsubsection{Graphite Probe Calorimeter 'Aerrow'}

The graphite probe calorimeter (GPC, referred to as Aerrow detector in literature) developed by Renaud et al. $[121,122]$ is the first graphite calorimeter being developed specifically for the clinical application in radiotherapy (see Fig. 12). It offers two modes of operation, isothermal and quasi-adiabatic. The relatively small form-factor and its handling in clinical practice resemble that of a Farmer-type ionization chamber, i.e. the GPC can be used in a standard clinical measurement setup with a typical water phantom or a water equivalent phantom. While vacuumbased thermal insulation is most common in graphite calorimetry applications, the GPC's insulating layers are built with aerogel material.

The feasibility of the GPC has been demonstrated for absolute dosimetry for high-energy photon and electron beams [122,123]. Its properties make it a promising candidate for standardized measurements of the absorbed dose of particle beams with ultra-high pulse dose

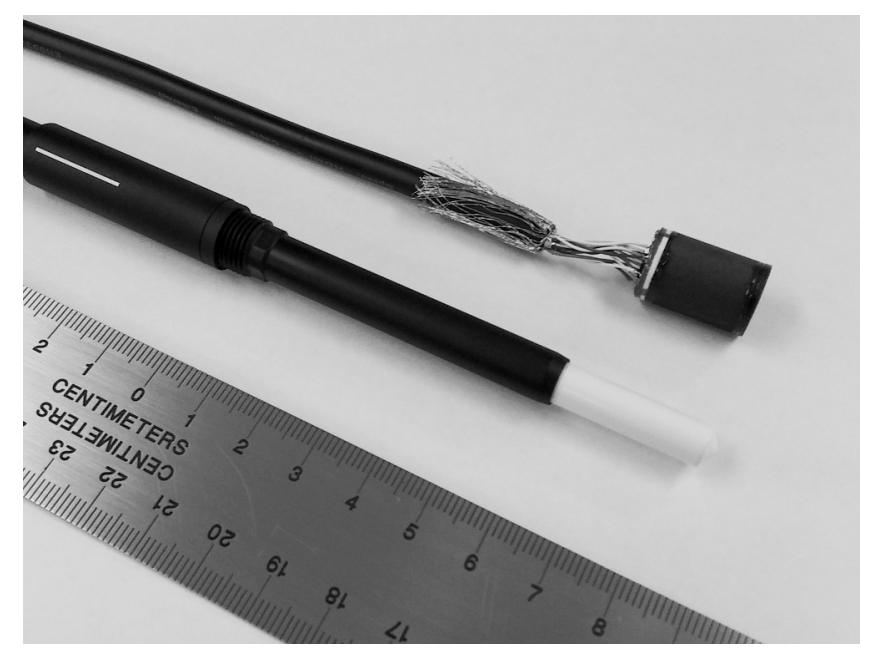

Fig. 12. A prototype of the Graphite Probe Calorimeter without its waterproof housing, next to a Sun Nuclear SNC 600c Farmer chamber for scale. The cylindrical graphite core (not visible) has a length of $10 \mathrm{~mm}$ and a diameter of $6.1 \mathrm{~mm}$. rates using the quasi-adiabatic mode of operation. Commercial prototypes of GPC are being developed at Sun Nuclear Corp. (Melbourne, FL, USA) and will be tested in UHPDR electron reference fields and in clinical FLASH beams within WP2 and WP3 of the UHDpulse project.

\subsubsection{Silicon diode detectors}

Semiconductor detectors (silicon and diamond) have been used for many years for active photon and charged particle radiotherapy dosimetry. Compared with an ionisation chamber of the same volume, they have a higher sensitivity thanks to their higher density and to the smaller ionization energy compared to the gas. Moreover, they can be fabricated with smaller sizes than ion chambers, providing high spatial resolution [124].

Typical silicon diodes used in dosimetry are based on P-N junctions where the surface of p-type bulk silicon is doped with an n-type element using ion diffusion or implantation techniques to create the junction. The built-in electrical field in the boundary between $\mathrm{p}$ and $\mathrm{n}$ silicon creates a carrier-free region, typically tenths of microns wide, that constitutes the sensitive volume of the detector.

The response of silicon diode dosimeters to ionizing radiation is complex and is affected by silicon material, previous irradiation history, dose rate and temperature [125-130]. Radiation damage forms recombination centres in the silicon, reducing the signal and consequently the sensitivity of the dosimeter with use. The recombination of charge carriers is also affected by the dose rate, as at high rates the recombination centres may become saturated, resulting in a non-linear response with dose per pulse. The creation of recombination centres is faster for the initial radiation exposure, so commercial silicon dosimeters are usually pre-irradiated to minimize this effect. However, regular calibrations of the diode response are still needed for accurate clinical dosimetry.

In recent years, silicon sensor technology has advanced thanks to the introduction of micromachining techniques that allow to create 3D structures out of silicon with resolution in the sub-micrometre range. Silicon detectors using this new technology ("3D") were pioneered by the UHDpulse partner CSIC-CNM for the high-luminosity particle physics experiments at CERN which have stringent demands regarding spatial resolution, speed of response and radiation hardness. These 3D detectors have micromachined electrodes that penetrate the silicon bulk, instead of being limited to the surface so charge collection distance and collection time are considerably shorter than in standard planar devices [131]. More recently this technology has been extended to produce silicon microdosimeters for hadrontherapy; these devices have well-defined collection volumes with dimensions of a few $\mu \mathrm{m}$ and charge collection times $<1 \mathrm{~ns}[132,133]$. The 3D microtechnology is also a promising option for dosimetry in UHPDR beams as the use of micronsized volumes (see Fig. 13) with very small inter-electrode distance should reduce the recombination effect in comparison to current silicon diode dosimeters.

In the framework of WP3 of the UHDpulse project, novel silicon microdosimeters will be evaluated as dosimeters in UHPDR proton and electron beams along with commercial available silicon dosimeters.

\subsubsection{Diamond detector}

A commercially available synthetic single crystal diamond detector is the microDiamond T60019 from PTW-Dosimetry. This detector has been characterized for relative dosimetry in large and small electron and photon beams [134-137]. Furthermore, this detector was evaluated for absolute photon dosimetry [138] and proton therapy [139-141]. Due to the high dose stability this detector is promising for the range of high and ultra-high dose per pulse. A first characterization in the range of high dose per pulse has already been performed [142]. The observed dosimetric properties indicate that the diamond detector is a suitable candidate for clinical electron beam dosimetry with high dose per pulse although a dose per pulse dependence could not been totally excluded. The investigation of the microDiamond in the ultra-high dose per pulse range is part of WP3 in this project. 


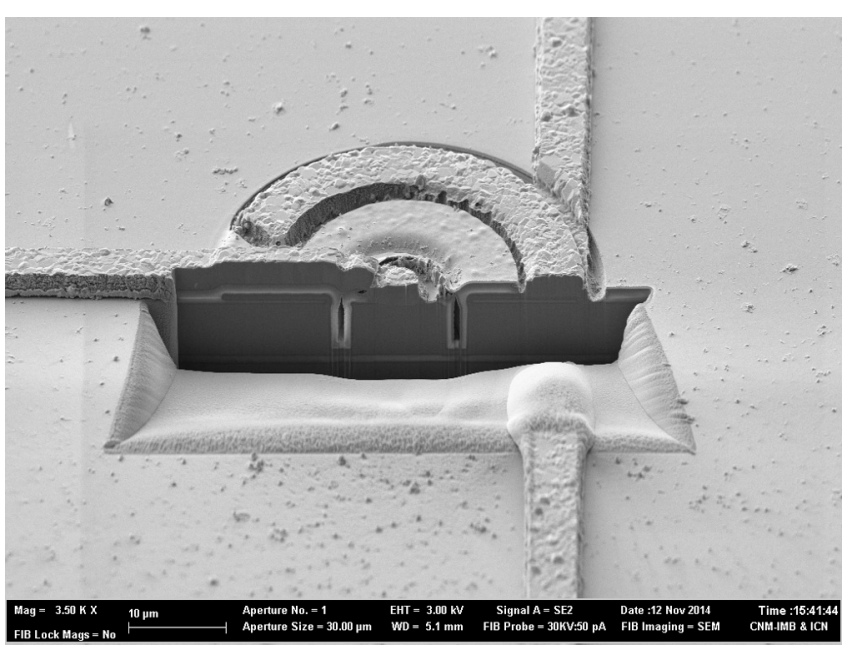

Fig. 13. SEM image of the section of a Si-microdosimeter. The central electrode is surrounded by a $3 \mathrm{D}$ trench electrode that delimits the active volume.

\subsubsection{TimePix 3 detector}

Utilizing of novel Timepix3 [143] detector is one of the techniques being explored in the framework of UHDpulse to improve current dosimetry and metrology to cope with UHPDR beams. The sensitive area of its semiconductor sensor is segmented to $256 \times 256$ very small pixels (each of $55 \times 55 \mu \mathrm{m}$ ). The pixelated detector provides the image of track for each detected particle. This imaging capability allows for distinguishing the particle types and their directions. Therefore, not only the total energy and intensity is recorded but composition of the radiation field can be extracted as well analyzing the shapes of the particle tracks.

The detector module for FLASH radiotherapy is based on "MiniPIXTPX3-Flex" device by ADVACAM (see Fig. 14 bottom right). It is adapted for operation immersed in water phantom. Its material composition is made tissue equivalent to minimize disturbances of the measured radiation field (Fig. 14 right). The sensor itself is either silicon or CdTe. Timepix 3 is a hybrid pixel detector readout chip, a successor to the Timepix chip, that can record time-of-arrival and energy simultaneously in each pixel. Timepix3 comes with a new data-driven readout architecture that allows for on-line readout of each hit pixel thanks to throughput of up to $40 \mathrm{Mhits} / \mathrm{s} / \mathrm{cm} 2$. This architecture allows simultaneous measurement and data acquisition, which reduce the dead-time virtually to zero.

Detectors based on TimePix3 are developed and tested in WP3 and WP4 of the UHDpulse project.

\subsection{Beam monitoring}

\subsubsection{Monitor chambers and current transformers for FLASH electron beams}

Ultra-high dose rate FLASH electron beams did not benefit from monitoring until now. Typically, the semi-transparent ionization chambers (ICs) used in conventional medical accelerators saturate when used under UHPDR conditions. Commercially available ultra-high dose rate electron accelerators did not solve this issue until now. Effectively, one can tailor a semi-transparent IC to UHPDR beams by decreasing the active volume, but would lose the sensitivity at conventional dose rate. The large dynamic range associated to a fast response, typically sub microseconds, make the design of monitor chambers difficult. Using two ICs in parallel could provide monitoring over a broader dose rate range. Such opportunity is planed to be explored.

In addition, it is planned to explore beam current transformers (BCT), such as AC Current Transformer (ACCT) or Integrating Current Transformer (ICT). These devices are promising, even though they are not used in clinical settings. However, beam physicists have develop a broad knowledge of BCT and commercial solution exists, such as from Bergoz Instrumentation (www.bergoz.com). At PTB's research electron accelerator, ICTs are already being used to precisely determine the charge of the beam pulses [144] (see Fig. 10). Typically, time resolution is not an issue with BCT, for example, ACCT resolve easily submicrosecond signals. The dynamic range issue can be circumvent by using two
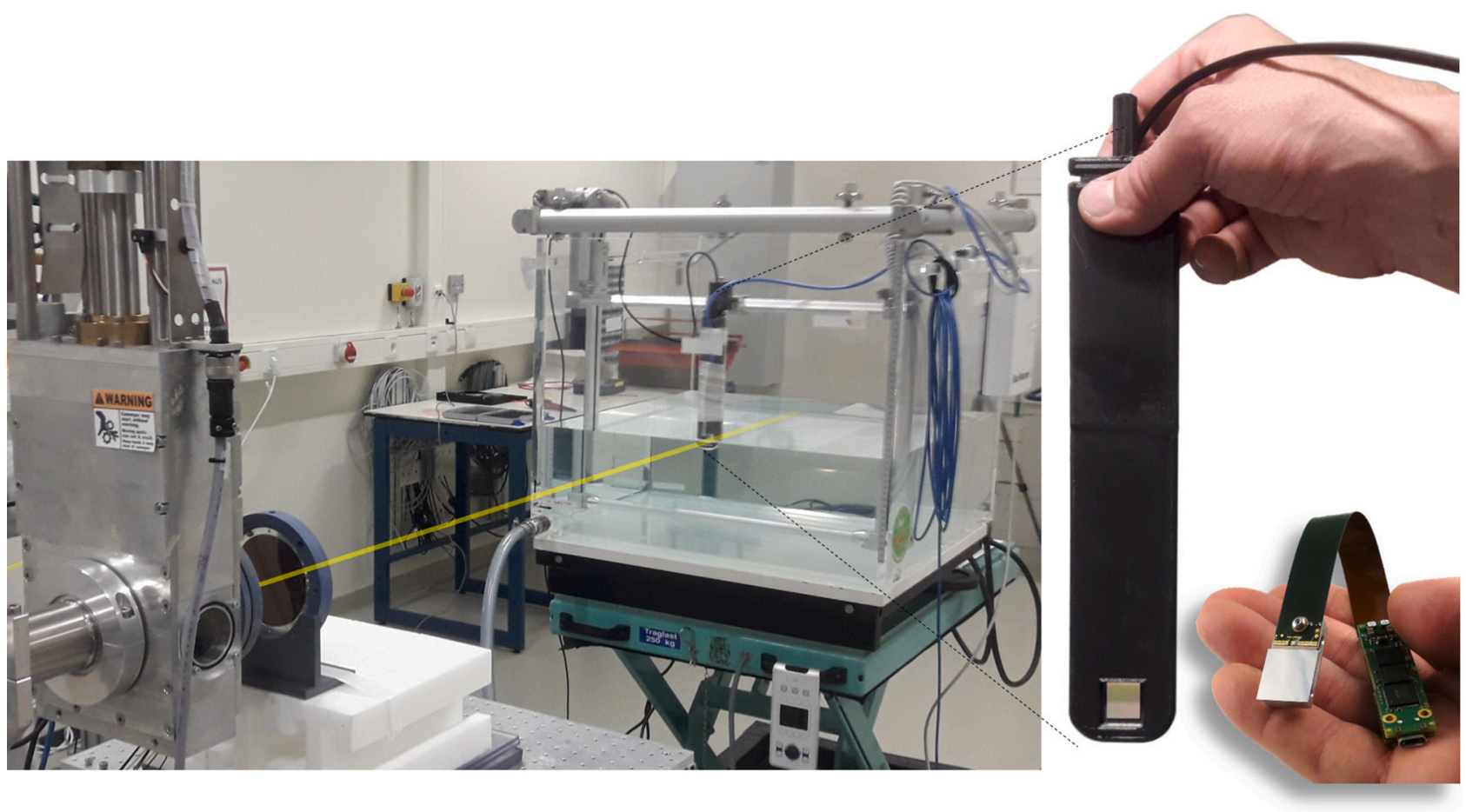

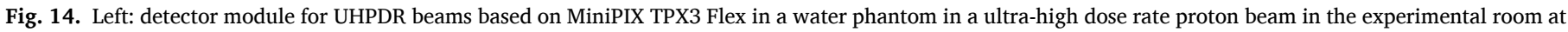
OncoRay Dresden. Yellow line indicates the proton beam axis. Right: detection module. Bottom right: Original "MiniPIX-TPX3-Flex" detector. 
data acquisition systems tailored for low and high amplitudes. If well designed and calibrated, the data recording can provide dosimetric data during the ultra-high dose rate irradiation. In the project it is planned to use BCTs in order to monitor UHPDR reference beams at NMIs, but also to develop pre-clinical monitoring systems based on this technology.

The connection of such monitoring system with the accelerator system to change the output is still a challenge. It seems possible to design feedback loops dealing with the output level between pulses, but the sub microsecond requirement of a monitoring during the pulse is not possible yet. Such system can be used as a safety system to insure the correct number of pulses delivered to the patient, but its resolution is directly dependent on the number of pulses.

\subsubsection{Monitor chambers for FLASH proton beams}

The current state of the art of beam monitors are air-filled transmission ionization chambers: they are well-established, easy to handle and show a high linearity for typical clinical proton beams. Some necessary correction factors like air pressure and temperature are easily accounted for and applied online routinely. The IBA proteus one solution is for example equipped with the so-called IC2/3 [145] ionisation chambers whose design and bias voltage were optimised to perform the beam monitoring during each therapy session in this limited clinical dose-rate range. With FLASH RT, however, the dose-rate (beam current density) is dramatically increased, which gives rise to recombination losses in these ICs. Indeed, these ICs have been designed to operate at a mean dose rate below $100 \mathrm{~Gy} / \mathrm{s}$ where their operating point does not suffer from saturation or non-linear behaviours. As these signal losses in the beam monitoring system would result in application of more radiation dose than intended, they have either to be accounted for or avoided using an adapted design. The former is technically more demanding, thus the latter is preferred if the beam physical parameters allow it. This is for instance the case for proton therapy systems based on quasicontinuous accelerators (like isochronous cyclotrons) and can be practically achieved by shrinking the electrode gap of the IC and/or increasing the applied high voltage. As an example, the ionisation chamber DOSION [146] has been modified to achieve ion recombination less than $1 \%$ for instantaneous dose-rates up to $1 \mathrm{kGy} / \mathrm{s}$. It also includes different current dividers from $1 / 100^{\text {th }}$ to $1 / 10000^{\text {th }}$ to avoid electrometer saturation. The dosimetric properties of a scanned beam and monitoring system were also studied in order to demonstrate the feasibility to monitor FLASH dose rates [147].

In WP3 of the UHDpulse project, a new transmission monitor chamber for FLASH proton beam is being investigated and further developed.

\subsection{Stray radiation}

All the therapeutic radiation beams studied in the project are characterized by the generation of secondary radiation fields with the same pulsed time structure as the primary beam. Such mixed fields are composed by radiation of different types and/or energy and cause parasitic doses to healthy tissue and critical organs outside the target volumes. This unwanted out of filed dose is crucial for the optimization of the therapy in view of a personalized dose management, as described in Ref. [148] paragraph 7.

The dosimetry of mixed radiation fields presents the difficulty caused by the necessity of proper identification of field components. In UHPDR beams the dosimetry is even more complicated due to the pulsed time structure of the field. Even if the stray radiation intensity is not high (and by no means ultra-high) the challenge of the short pulse duration limits the availability of detectors. Passive detectors can still be used, but concerning active detectors, their capability of coping with pulsed fields must be demonstrated.

\subsubsection{Photons, electrons and protons}

Stray radiation field consists mainly from photons and electrons.
Depending on primary beam parameters and measurement position, protons, neutrons, and ions can contribute to the stray radiation dose as well. The key requirement from a stray radiation detector is the possibility to distinguish particle types. This is fulfilled with a Timepix3 detector with an appropriate silicon or CdTe sensor [143]. It is a novel active pixelized semiconductor device possessing high spatial, energy and time resolution (1.6 ns) that allows the visualization of individual charged particle tracks. Thus, the detector characteristics provide unique possibility to distinguish different types of particles according to their track structure even in pulsed fields with high count rates per pulse.

Within WP4 of the UHDpulse project, the Timepix3 detector will be optimized for the use specifically for detection of stray radiation inside a water phantom. Experiments and Monte Carlo simulations will be exploited to find optimal sensor parameters and detector design. The methodology will be developed to qualify and quantify different particle track types measured by the optimized detector in UHPDR stray radiation fields and finally to determine absorbed dose to water and subsequently equivalent dose. Validation of the methodology will be performed in reference fields.

\subsubsection{Neutrons}

In case the energy of the primary beam is above the threshold of neutron generation (about $6 \mathrm{MeV}$ ) the stray radiation is composed by a mixed neutron/photon field and the proportion of the two components can vary depending on the primary particles and their energy. An active neutron detector must simultaneously cope with the short pulse duration and the photon discrimination. Neutrons represents the most penetrating component of the stray radiation field and its energy distribution is strongly dependent on the measuring position with respect to the direction of the primary beam [149]. For this reason, a full characterization of the neutron field includes both dosimetry and spectrometry. In recent years a new rem-counter, called LUPIN, especially designed for pulsed field was developed [150-153] and it is now available on the market. The working principle of this device is based on the measurement of the total charge generated in the thermal neutron sensitive proportional counter hosted in the center of a neutron moderator. This detector can be effectively used for dosimetry and the issue of neutron spectrometry is tackled adapting the LUPIN technology to the well known technique of the Bonner Sphere Spectrometer (BSS). The existing BSS normally used at NPL $[154,155]$ will be adapted to the LUPIN electronics and the response functions of the BSS will be recalculated with Monte Carlo simulations. The simulated response functions will be validated with irradiation to monoenergetic neutrons at NPL and tested in workplaces fields exhibiting a pulsed time structure.

\section{The UHDpulse project}

\subsection{Consortium}

The UHDpulse project brings together leading European National Metrology Institutes (NMI) in the field of radiation dosimetry with leading universities, research institutes and academic hospitals in the field of radiotherapy and radiation detector developments to deliver standardized, practicable and traceable dose measurements for the application of particle beams with ultra-high pulse dose rates, i.e. with ultra-high dose per pulse or with ultra-short pulse duration. In total five NMIs (PTB - Germany, CMI - Czech Republic, METAS - Switzerland, GUM - Poland, and NPL - United Kingdom), two academic hospitals (CHUV - Switzerland, and Institut Curie - France), three universities (PoliMi - Italy, QUB - United Kingdom, and USC - Spain), three national research institutes (IMB-CNM, CSIC - Spain, NPI - Czech Republic, and HZDR - Germany), one European research institute (ELI - Czech Republic) and two companies (ADVACAM - Czech Republic, and PTW Germany) are included as partner. Interested institutions that want to contribute to the goals of the project may join as Collaborator (Up to 
now: University of Oldenburg, Sun Nuclear Corp., Varian Medical Systems, LPC CAEN, IBA Dosimetry, INSPIRE (https://protonsinspire.eu/), MedAustron, National Research Council Canada, Université Laval, Sordina IORT Technologies, and DE.TEC.TOR. Devices \& Technologies Torino).

\subsection{Objectives}

The overall goal of the project is to provide the metrological tools needed to establish traceability in absorbed dose measurements of UHPDR particle beams. These tools are a prerequisite for the comparison of radiobiological effectiveness for different irradiation modalities and sites; they are essential to carry out pre-clinical radiobiological studies to test and compare the efficacy of these beams, and to enable future clinical application of these emerging technologies.

The specific objectives of the project are:

- To develop a metrological framework, including SI-traceable primary and secondary reference standards and validated reference methods for dosimetry measurements for particle beams with ultrahigh pulse dose rates.

- To characterise the response of available detector systems in particle beams with ultra-high dose per pulse or with ultra-short pulse duration.

- To develop traceable and validated methods for relative dosimetry and for the characterisation of stray radiation outside the primary pulsed particle beams.

- To provide the input data for future Codes of Practice for absolute dose measurements in particle beams with ultra-high pulse dose rates.

\subsection{Work packages}

The partners will fulfill the aim of the project in four technical WPs (see Fig. 15). Most partners are involved in all WPs.
WP1: SI-traceable primary standards for absorbed dose measurements. The aim of WP1, led by NPL, is to provide the metrological input needed to support absolute dosimetry of UHPDR particle beams, generated with conventional as well as laser-driven accelerators. The work includes establishment of Fricke dosimetry, water calorimetry and graphite calorimetry primary standards for the absorbed dose measurements due to UHPDR electron and proton beams, and initiation of developments of graphite calorimeters for absolute dosimetry for laser-driven electron and proton beams. The work in this WP will also lead to the establishment of the reference UHPDR radiation fields for electron beams enabling traceable calibrations for FLASH electron RT.

WP2: Secondary standards and reference methods for reference and relative dosimetry. The aim of WP2, led by METAS, is to transfer traceable dosimetry into clinical and pre-clinical UHPDR beam accelerators. Part of this WP concentrates on the transfer from the primary standards developed in WP1 to their implementation in the reference dosimetry at (pre-) clinical facilities using FLASH electron accelerators, laser driven accelerators, or VHEE beams. The partners will determine already established measurement systems suitable to become secondary standards for FLASH electron beams and test their characteristics required for metrological and clinical use. This WP also deals with the establishment of necessary metrological framework required for the development of clinically relevant working protocols in FLASH RT which will serve as an input for future code of practice.

WP3: Detector systems for measurements in the primary beam. The aim of WP3, led by CHUV, is to evaluate novel absolute and relative dosimetric systems compatible with pre-clinical and clinical UHPDR FLASH and laser-driven accelerators. In complement to WP2, this WP explores novel and custom-build detectors as well as beam monitoring systems. Work effort in this WP will be crowned by an intercomparison of the considered detector systems in respective UHPDR particle beams.

WP4: Detector systems and methods for dosimetry outside primary beam. The WP4, led by ADVACAM, is focused on the development of traceable and validated methods for characterisation of stray radiation outside the UHPDR primary particle beam. The results of this WP will lead to the

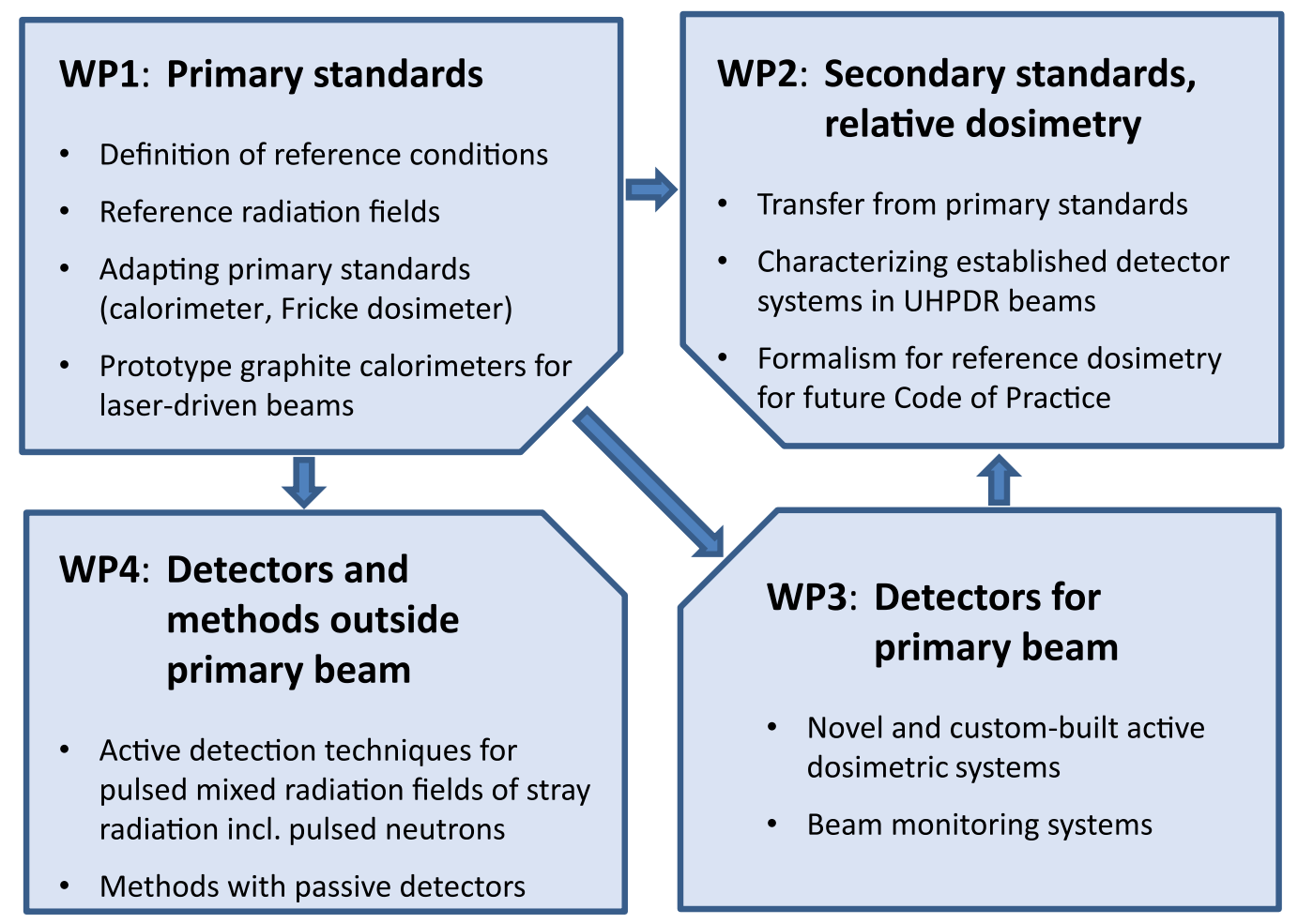

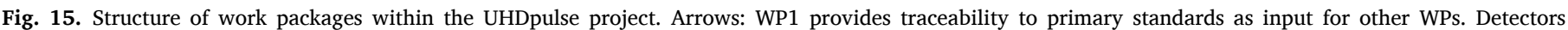
developed and tested in WP3 may used as secondary standards mentioned in new dosimetry formalism. 
compilation of a Best Practice Guide for the characterization of stray radiation outside UHPDR particle beams.

\section{Conclusion}

A brief review is given about the current developments of emerging radiotherapy techniques exploiting pulsed particle beams with high doses per pulse. Various sources generating pulsed beams of ionizing particles are being developed, namely FLASH electron and proton beams, Very High Energy Electron (VHEE) beams, and laser-driven electron and proton beams. One of the current limitations for these new radiotherapy techniques is the lack of clinical reference dosimetry traceable to national metrology standards. Due to ultra-high dose rates and pulsed structure of the beams, it is not possible to simply apply Codes of Practice available for dosimetry in conventional external radiotherapy. The European project "Metrology for advanced radiotherapy using particle beams with ultra-high pulse dose rates" aims to develop metrological tools needed to establish traceability in absorbed dose measurements of ultra-high pulse dose rate particle beams. These tools are necessary for accurate comparison of radiobiological experiments, to compare the efficacy and to enable future clinical application of these beams.

\section{Acknowledgements}

This project has received funding from the EMPIR programme cofinanced by the Participating States and from the European Union's Horizon 2020 research and innovation programme.

\section{References}

[1] Borras J, Lievens Y, Barton M, Corral J, Ferlay J, Bray F, Grau C. How many new cancer patients in Europe will require radiotherapy by 2025? An ESTRO-HERO analysis. Radiother Oncol 2016;119(1):5-11. https://doi.org/10.1016/j. radonc. 2016.02.016. ISSN 0167-8140.

[2] Siva S, Pham D, Gill S, Corcoran NM, Foroudi F. A systematic review of stereotactic radiotherapy ablation for primary renal cell carcinoma. BJU Int 2012;110(11b):E737-43. https://doi.org/10.1111/j.1464-410x.2012.11550.x. ISSN 1464-4096.

[3] Haridass A. Developments in Stereotactic Body Radiotherapy. Cancers 2018;10 (30544488):497. https://doi.org/10.3390/cancers10120497. ISSN 2072-6694.

[4] Lindberg K, Bergström P, Brustugun OT, Engelholm S, Grozman V, Hoyer M, Karlsson K, et al. OA24.05 The Nordic HILUS-Trial - First Report of a Phase II Trial of SBRT of Centrally Located Lung Tumors. J Thoracic Oncol 2017;12(1, Suppl.):S340. https://doi.org/10.1016/j.jtho.2016.11.369. ISSN 1556-0864.

[5] Packer RJ, Zhou T, Holmes E, Vezina G, Gajjar A. Survival and secondary tumors in children with medulloblastoma receiving radiotherapy and adjuvant chemotherapy: results of Children's Oncology Group trial A9961. Neuro Oncol 2012;15(1):97-103. https://doi.org/10.1093/neuonc/nos267. ISSN 1522-8517.

[6] Salloum R, Chen Y, Yasui Y, Packer R, Leisenring W, Wells E, et al. Late morbidity and mortality among medulloblastoma survivors diagnosed across three decades: a report from the childhood cancer survivor study. JCO 2020;37(9):731-40. https://doi.org/10.1200/jco.18.00969. ISSN 0732-183X.

[7] Lee N, Chuang C, Quivey JM, Phillips TL, Akazawa P, Verhey LJ, Xia P. Skin toxicity due to intensity-modulated radiotherapy for head-and-neck carcinoma. Int J Radiat Oncolo Biol Phys 2002;53(3):630-7. https://doi.org/10.1016/ S0360-3016(02)02756-6. ISSN 0360-3016.

[8] Baumann M, Krause M, Overgaard J, Debus J, Bentzen SM, Daartz J, Richter C, Zips D, Bortfeld T. Radiation oncology in the era of precision medicine. Nat Rev Cancer 2016;16(4):234-49. https://doi.org/10.1038/nrc.2016.18. ISSN 14741768.

[9] Fotouhi Ghiam A, Dawson LA, Abuzeid W, Rauth S, Jang RW, Horlick E, Bezjak A. Role of palliative radiotherapy in the management of mural cardiac metastases: who, when and how to treat? A case series of 10 patients. Cancer Med 2020;5(6): 989-96. https://doi.org/10.1002/cam4.619. ISSN 2045-7634.

[10] Shah GD, Yahalom J, Correa DD, Lai RK, Raizer JJ, Schiff D, LaRocca R, Grant B, DeAngelis LM, Abrey LE. Combined Immunochemotherapy With Reduced WholeBrain Radiotherapy for Newly Diagnosed Primary CNS Lymphoma. JCO 2020;25 (30):4730-5. https://doi.org/10.1200/jco.2007.12.5062. ISSN 0732-183X.

[11] DeAngelis LM. Whither whole brain radiotherapy for primary CNS lymphoma? Neuro Oncol 2014;16(8):1032-4. https://doi.org/10.1093/neuonc/nou122. ISSN 1522-8517.

[12] Berry RJ, Hall EJ, Forster DW, Storr TH, Goodman MJ. Survival of mammalian cells exposed to X rays at ultra-high dose-rates. BJR 1969;42(494):102-7. https:// doi.org/10.1259/0007-1285-42-494-102. ISSN 0007-1285.

[13] Favaudon V, Caplier L, Monceau V, Pouzoulet F, Sayarath M, Fouillade C, Poupon M-F, Brito I, Hupé P, Bourhis J, Hall J, Fontaine J-J, Vozenin M-C.
Ultrahigh dose-rate FLASH irradiation increases the differential response between normal and tumor tissue in mice. Sci Transl Med 2014;6(245). https://doi.org/ 10.1126/scitranslmed.3008973. 245ra93.

[14] Loo BW, Schuler E, Lartey FM, Rafat M, King GJ, Trovati S, Koong AC, Maxim PG. (P003) Delivery of ultra-rapid flash radiation therapy and demonstration of normal tissue sparing after abdominal irradiation of mice. Int $\mathrm{J}$ Radiat Oncol Biol Phys 2017;98(2, Suppl.):E16, ISSN 0360-3016, doi: 10.1016/j. ijrobp.2017.02.101.

[15] Vozenin M-C, De Fornel P, Petersson K, Favaudon V, Jaccard M, Germond J-F, Petit B, Burki M, Ferrand G, Patin D, Bouchaab H, Ozsahin M, Bochud F, Bailat C, Devauchelle P, Bourhis J. The Advantage of FLASH Radiotherapy Confirmed in Mini-pig and Cat-cancer Patients. Clin Cancer Res 2019;25(1):35. https://doi. org/10.1158/1078-0432.CCR-17-3375.

[16] Vozenin M-C, Hendry JH, Limoli CL. Biological Benefits of Ultra-high Dose Rate FLASH Radiotherapy: Sleeping Beauty Awoken. Clin Oncol 2019;31(7):407-15. https://doi.org/10.1016/j.clon.2019.04.001. ISSN 0936-6555.

[17] Simmons DA, Lartey FM, Schüler E, Rafat M, King G, Kim A, Ko R, Semaan S, Gonzalez S, Jenkins M, Pradhan P, Shih Z, Wang J, von Eyben R, Graves EE, Maxim PG, Longo FM, Loo BW. Reduced cognitive deficits after FLASH irradiation of whole mouse brain are associated with less hippocampal dendritic spine loss and neuroinflammation. Radiother Oncol 2019;139:4-10. https://doi. org/10.1016/j.radonc.2019.06.006. ISSN 0167-8140.

[18] Montay-Gruel P, Acharya MM, Petersson K, Alikhani L, Yakkala C, Allen BD, Ollivier J, Petit B, Jorge PG, Syage AR, Nguyen TA, Baddour AAD, Lu C, Singh P, Moeckli R, Bochud F, Germond J-F, Froidevaux P, Bailat C, Bourhis J, Vozenin MC, Limoli CL. Long-term neurocognitive benefits of FLASH radiotherapy driven by reduced reactive oxygen species. Proc Natl Acad Sci USA 2019;116(22):10943. https://doi.org/10.1073/pnas.1901777116.

[19] Bourhis J, Sozzi WJ, Jorge PG, Gaide O, Bailat C, Duclos F, Patin D, Ozsahin M, Bochud F, Germond J-F, Moeckli R, Vozenin M-C. Treatment of a first patient with FLASH-radiotherapy. Radiother Oncol 2019;139:18-22. https://doi.org/ 10.1016/j.radonc.2019.06.019. ISSN 0167-8140.

[20] Levy K, Natarajan S, Wang J, Chow S, Eggold J, Loo P, Manjappa R, Lartey FM, Schüler E, Skinner L, Rafat M, Ko R, Kim A, Al Rawi D, von Eyben R, Dorigo O, Casey KM, Graves EE, Bush K, Yu AS, Koong AC, Maxim PG, Loo BW, Rankin EB. FLASH irradiation enhances the therapeutic index of abdominal radiotherapy in mice 2019;bioRxiv 2019(12). https://doi.org/10.1101/2019.12.12.873414. 12.873414 .

[21] Diffenderfer ES, Verginadis II, Kim MM, Shoniyozov K, Velalopoulou A, Goia D, Putt M, Hagan S, Avery S, Teo K, Zou W, Lin A, Swisher-McClure S, Koch C, Kennedy AR, Minn A, Maity A, Busch TM, Dong L, Koumenis C, Metz J, Cengel KA. Design Implementation and in Vivo Validation of a Novel Proton FLASH Radiation Therapy System. Int J Radiat Oncol Biol Phys 2020;106(2): 440-8. https://doi.org/10.1016/j.ijrobp.2019.10.049. ISSN 0360-3016.

[22] Jaccard M, Durän MT, Petersson K, Germond J-F, Liger P, Vozenin M-C, Bourhis J, Bochud F, Bailat C. High dose-per-pulse electron beam dosimetry: commissioning of the Oriatron eRT6 prototype linear accelerator for preclinical use. Med Phys 2018;45(2):863-74. https://doi.org/10.1002/mp.12713. ISSN 0094-2405.

[23] Schueler E, Trovati S, King G, Lartey F, Rafat M, Loo B, Maxim P. TU-H-CAMPUSTeP2-02: FLASH Irradiation Improves the Therapeutic Index Following GI Tract Irradiation. Med Phys 2016;43(6Part37):3783. https://doi.org/10.1118/ 1.4957690. ISSN 0094-2405.

[24] Venkatesulu BP, Sharma A, Pollard-Larkin JM, Sadagopan R, Symons J, Neri S, Singh PK, Tailor R, Lin SH, Krishnan S. Ultra high dose rate $(35 \mathrm{~Gy} / \mathrm{sec})$ radiation does not spare the normal tissue in cardiac and splenic models of lymphopenia and gastrointestinal syndrome. Sci Rep 9(17180), doi: 10.1038/s41598-01953562-y.

[25] Wilson JD, Hammond EM, Higgins GS, Petersson K. Ultra-High Dose Rate (FLASH) Radiotherapy: Silver Bullet or Fool's Gold? Front Oncol 2020;9:1563. https://doi.org/10.3389/fonc.2019.01563. ISSN 2234-943X.

[26] Hogstrom KR, Almond PR. Review of electron beam therapy physics. Phys Med Biol 2006;51(13):R455-89. https://doi.org/10.1088/0031-9155/51/13/R25. ISSN 1361-6560.

[27] DesRosiers C, Moskvin V, Bielajew AF, Papiez L. 150-250 MeV electron beams in radiation therapy. Phys Med Biol 2000;45(7):1781-805. https://doi.org/ 10.1088/0031-9155/45/7/306. ISSN 1361-6560.

[28] Leemans WP, Nagler B, Gonsalves AJ, Tóth C, Nakamura K, Geddes CGR, Esarey E, Schroeder CB, Hooker SM. GeV electron beams from a centimetre-scale accelerator. Nat Phys 2006;2(10):696-9. ISSN 1745-2481. URL: https://doi.org/ 10.1038/nphys418.

[29] Fuchs T, Szymanowski H, Oelfke U, Glinec Y, Rechatin C, Faure J, Malka V. Treatment planning for laser-accelerated very-high energy electrons. Phys Med Biol 2009;54(11):3315-28. https://doi.org/10.1088/0031-9155/54/11/003. ISSN 1361-6560.

[30] Karsch L, Beyreuther E, Enghardt W, Gotz M, Masood U, Schramm U, Zeil K, Pawelke J. Towards ion beam therapy based on laser plasma accelerators. Acta Oncologica 2017;56(11):1359-66. https://doi.org/10.1080/ 0284186x.2017.1355111. ISSN 0284-186X. URL: https://doi.org/10.1080/ 0284186X.2017.1355111.

[31] McManus M, Romano F, Lee ND, Farabolini W, Gilardi A, Royle G, Palmans H, Subiel A. The challenge of ionisation chamber dosimetry in ultra-short pulsed high dose-rate Very High Energy Electron beams. Nat Sci Rep 10(9089), doi: 10.1038/s41598-020-65819-y.

[32] Oppelt M, Baumann M, Bergmann R, Beyreuther E, Brüchner K, Hartmann J, Karsch L, Krause M, Laschinsky L, Leßmann E, Nicolai M, Reuter M, Richter C, 
Sävert A, Schnell M, Schürer M, Woithe J, Kaluza M, Pawelke J. Comparison study of in vivo dose response to laser-driven versus conventional electron beam. Radiat Environ Biophys 2015;54(2):155-66. ISSN 1432-2099. URL: https://doi. org/10.1007/s00411-014-0582-1.

[33] Bin J, Allinger K, Assmann W, Dollinger G, Drexler GA, Friedl AA, Habs D, Hilz P, Hoerlein R, Humble N, Karsch S, Khrennikov K, Kiefer D, Krausz F, Ma W, Michalski D, Molls M, Raith S, Reinhardt S, Röper B, Schmid TE, Tajima T, Wenz J, Zlobinskaya O, Schreiber J, Wilkens JJ. A laser-driven nanosecond proton source for radiobiological studies. Appl Phys Lett 2012;101(24):243701. https://doi.org/10.1063/1.4769372. ISSN 0003-6951. URL: https://doi.org/ 10.1063/1.4769372.

34] Patriarca A, Fouillade C, Auger M, Martin F, Pouzoulet F, Nauraye C, et al. Experimental Set-up for FLASH Proton Irradiation of Small Animals Using Clinical System. Int J Radiat Oncol Biol Phys 2018;102(3):619-626, ISSN 0360 3016, doi: 10.1016/j.ijrobp.2018.06.403.

[35] Petersson K, Jaccard M, Germond J-F, Buchillier T, Bochud F, Bourhis J, Vozenin M-C, Bailat C. High dose-per-pulse electron beam dosimetry - A model to correct for the ion recombination in the Advanced Markus ionization chamber. Med Phys 2017;44(3):1157-67. https://doi.org/10.1002/mp.12111. ISSN 0094 2405.

[36] Bourhis J, Montay-Gruel P, Gonçalves Jorge P, Bailat C, Petit B, Ollivier J, Jeanneret-Sozzi W, Ozsahin M, Bochud F, Moeckli R, Germond J-F, Vozenin M-C. Clinical translation of FLASH radiotherapy: Why and how? Radiother Oncol 2019;139:11-7. https://doi.org/10.1016/j.radonc.2019.04.008. ISSN 01678140 .

[37] Fouillade C, Curras-Alonso S, Giuranno L, Quelennec E, Heinrich S, BonnetBoissinot S, Beddok A, Leboucher S, Karakurt HU, Bohec M, Baulande S, Vooijs M, Verrelle P, Dutreix M, Londoño-Vallejo A, Favaudon V. FLASH irradiation spare lung progenitor cells and limits the incidence of radio-induced senescence. Clin Cancer Res 2019. https://doi.org/10.1158/1078-0432.CCR-19-1440. clincanres.1440.2019.

[38] Montay-Gruel P, Petersson K, Jaccard M, Boivin G, Germond J-F, Petit B, Doenlen R, Favaudon V, Bochud F, Bailat C, Bourhis J, Vozenin M-C. Irradiation in a flash: Unique sparing of memory in mice after whole brain irradiation with dose rates above 100Gy/s. Radiother Oncol 2017;124(3):365-9. https://doi.org/ 10.1016/j.radonc.2017.05.003. ISSN 0167-8140.

[39] Field SB, Bewley DK. Effects of dose-rate on the radiation response of rat skin. Int J Radiat Biol Related Stud Phys Chem Med 1974;26(3):259-67. https://doi.org/ 10.1080/09553007414551221. ISSN 0020-7616.

[40] Schüler E, Trovati S, King G, Lartey F, Rafat M, Villegas M, Praxel AJ, Loo BW, Maxim PG. Experimental Platform for Ultra-high Dose Rate FLASH Irradiation of Small Animals Using a Clinical Linear Accelerator. Int J Radiat Oncol Biol Phys 2017;97(1):195-203. https://doi.org/10.1016/j.ijrobp.2016.09.018. ISSN 0360 3016

[41] Pratx G, Kapp DS. A computational model of radiolytic oxygen depletion during FLASH irradiation and its effect on the oxygen enhancement ratio. Phys Med Bio 2019;64(18):185005. https://doi.org/10.1088/1361-6560/ab3769. ISSN 13616560.

[42] Spitz DR, Buettner GR, Petronek MS, St-Aubin JJ, Flynn RT, Waldron TJ, Limoli CL. An integrated physico-chemical approach for explaining the differential impact of FLASH versus conventional dose rate irradiation on cance and normal tissue responses. Radiother Oncol 2019;139:23-7. https://doi.org/ 10.1016/j.radonc.2019.03.028. ISSN 0167-8140.

43] Berry RJ, Stedeford JBH. Reproductive survival of mammalian cells after irradiation at ultra-high dose-rates: further observations and their importance for radiotherapy. BJR 2020;45(531):171-7. https://doi.org/10.1259/0007-1285-45 531-171. ISSN 0007-1285.

[44] Adrian G, Konradsson E, Lempart M, Bäck S, Ceberg C, Petersson K. The FLASH effect depends on oxygen concentration. BJR 2019. https://doi.org/10.1259/ bjr.20190702. 20190702. ISSN 0007-1285.

45] Vordermark D, Horsman MR. Hypoxia as a biomarker and for personalized radiation oncology. In: Baumann M, Krause M, Cordes N, editors. Molecular radio-oncology. Recent results in cancer research; vol. 198, Berlin, Heidelberg: Springer; 2016. doi: 10.1007/978-3-662-49651-0_6.

[46] Alexander MS, Wilkes JG, Schroeder SR, Buettner GR, Wagner BA, Du J, GibsonCorley K, O'Leary BR, Spitz DR, Buatti JM, Berg DJ, Bodeker KL, Vollstedt S, Brown HA, Allen BG, Cullen JJ. Pharmacologic ascorbate reduces radiationinduced normal tissue toxicity and enhances tumor radiosensitization in pancreatic cancer. Cancer Res 2018;78(24):6838-51. https://doi.org/10.1158/ 0008-5472.CAN-18-1680. ISSN 0008-5472. URL:https://cancerres.aacrjournals. org/content/78/24/6838.

[47] Willett CG, Czito BG, Tyler DS. Intraoperative radiation therapy. JCO 2007;25(8): 971-7. https://doi.org/10.1200/jco.2006.10.0255. ISSN 0732-183X.

[48] Azinovic I, Calvo FA, Puebla F, Aristu J, Martinez-Monge R. Long-term normal tissue effects of intraoperative electron radiation therapy (IOERT): late sequelae, tumor recurrence, and second malignancies. Int J Radiat Oncol Biol Phys 2001;49 (2):597-604. https://doi.org/10.1016/S0360-3016(00)01475-9. ISSN 03603016.

[49] Buonanno M, Grilj V, Brenner DJ. Biological effects in normal cells exposed to FLASH dose rate protons. Radiother Oncol 2019;139:51-5. https://doi.org/ 10.1016/j.radonc.2019.02.009. ISSN 0167-8140.

[50] Schmid TE, Dollinger G, Hauptner A, Hable V, Greubel C, Auer S, Friedl AA, Molls M, Röper B. No Evidence for a Different RBE between Pulsed and Continuous $20 \mathrm{MeV}$ Protons. Radiat Res 2009;172(5):567-74. https://doi.org/ 10.1667/RR1539.1.
[51] Schmid TE, Dollinger G, Hable V, Greubel C, Zlobinskaya O, Michalski D, Molls M, Röper B. Relative biological effectiveness of pulsed and continuous 20 $\mathrm{MeV}$ protons for micronucleus induction in 3D human reconstructed skin tissue. Radiother Oncol 2010;95(1):66-72. https://doi.org/10.1016/j. radonc 2010.03.010. ISSN 0167-8140.

[52] Yogo A, Maeda T, Hori T, Sakaki H, Ogura K, Nishiuchi M, Sagisaka A, Kiriyama H, Okada H, Kanazawa S, Shimomura T, Nakai Y, Tanoue M, Sasao F, Bolton PR, Murakami M, Nomura T, Kawanishi S, Kondo K. Measurement of relative biological effectiveness of protons in human cancer cells using a laserdriven quasimonoenergetic proton beamline. Appl Phys Lett 2011;98(5). https:// doi.org/10.1063/1.3551623. 053701, ISSN 0003-6951.

[53] Auer S, Hable V, Greubel C, Drexler GA, Schmid TE, Belka C, Dollinger G, Friedl AA. Survival of tumor cells after proton irradiation with ultra-high dose rates. Radiat Oncol 2011;6(1):139. https://doi.org/10.1186/1748-717X-6-139. ISSN 1748-717X.

[54] Kraft SD, Richter C, Zeil K, Baumann M, Beyreuther E, Bock S, Bussmann M, Cowan TE, Dammene Y, Enghardt W, Helbig U, Karsch L, Kluge T, Laschinsky L, Lessmann E, Metzkes J, Naumburger D, Sauerbrey R, Schürer M, Sobiella M, Woithe J, Schramm U, Pawelke J. Dose-dependent biological damage of tumour cells by laser-accelerated proton beams. New J Phys 2010;12(8). https://doi.org/ 10.1088/1367-2630/12/8/085003. 085003, ISSN 1367-2630.

[55] Zeil K, Baumann M, Beyreuther E, Burris-Mog T, Cowan TE, Enghardt W, Karsch L, Kraft SD, Laschinsky L, Metzkes J, Naumburger D, Oppelt M, Richter C, Sauerbrey R, Schürer M, Schramm U, Pawelke J. Dose-controlled irradiation of cancer cells with laser-accelerated proton pulses. Appl Phys B 2013;110(4): 437-44. https://doi.org/10.1007/s00340-012-5275-3. ISSN 1432-0649.

[56] Doria D, Kakolee KF, Kar S, Litt SK, Fiorini F, Ahmed H, Green S, Jeynes JCG, Kavanagh J, Kirby D, Kirkby KJ, Lewis CL, Merchant MJ, Nersisyan G, Prasad R, Prise KM, Schettino G, Zepf M, Borghesi M. Biological effectiveness on live cells of laser driven protons at dose rates exceeding $109 \mathrm{~Gy} / \mathrm{s}$. AIP Adv 2012;2(1): 011209. https://doi.org/10.1063/1.3699063.

[57] Hanton F, Chaudhary P, Doria D, Gwynne D, Maiorino C, Scullion C, Ahmed H, Marshall T, Naughton K, Romagnani L, Kar S, Schettino G, McKenna P, Botchway S, Symes DR, Rajeev PP, Prise KM, Borghesi M. DNA DSB repair dynamics following irradiation with laser-driven protons at ultra-high dose rates. Sci Rep 2019;9(1):4471. https://doi.org/10.1038/s41598-019-40339-6. ISSN 2045-2322.

[58] Schmid TE, Dollinger G, Hable V, Greubel C, Zlobinskaya O, Michalski D, Auer S, Friedl AA, Schmid E, Molls M, Röper B. The Effectiveness of $20 \mathrm{MeV}$ Protons at Nanosecond Pulse Lengths in Producing Chromosome Aberrations in HumanHamster Hybrid Cells. Radiat Res 2011;175(6):719-27. https://doi.org/10.1667/ RR2465.1.

[59] Raschke S, Spickermann S, Toncian T, Swantusch M, Boeker J, Giesen U, Iliakis G, Willi O, Boege F. Ultra-short laser-accelerated proton pulses have similar DNAdamaging effectiveness but produce less immediate nitroxidative stress than conventional proton beams. Sci Rep 2016;6(1). https://doi.org/10.1038/ srep32441. 32441, ISSN 2045-2322.

[60] Manti L, Perozziello FM, Borghesi M, Candiano G, Chaudhary P, Cirrone GAP, Doria D, Gwynne D, Leanza R, Prise KM, Romagnani L, Romano F, Scuderi V, Tramontana A. The radiobiology of laser-driven particle beams: focus on sublethal responses of normal human cells. J Instrum 2017;12(03):C03084. https:// doi.org/10.1088/1748-0221/12/03/C03084. ISSN 1748-0221.

[61] Pommarel L, Vauzour B, Mégnin-Chanet F, Bayart E, Delmas O, Goudjil F, Nauraye C, Letellier V, Pouzoulet F, Schillaci F, Romano F, Scuderi V, Cirrone GAP, Deutsch E, Flacco A, Malka V. Spectral and spatial shaping of a laser-produced ion beam for radiation-biology experiments. PRAB 2017;20(3): 032801. https://doi.org/10.1103/PhysRevAccelBeams.20.032801.

[62] Bayart E, Flacco A, Delmas O, Pommarel L, Levy D, Cavallone M, MegninChanet F, Deutsch E, Malka V. Fast dose fractionation using ultra-short laser accelerated proton pulses can increase cancer cell mortality, which relies on functional PARP1 protein. Sci Rep 2019;9(1). https://doi.org/10.1038/s41598019-46512-1. 10132, ISSN 2045-2322.

[63] Beyreuther E, Brand M, Hans S, Hideghéty K, Karsch L, Leßmann E, Schürer M, Szabó ER, Pawelke J. Feasibility of proton FLASH effect tested by zebrafish embryo irradiation. Radiother Oncol 2019;139:46-50. https://doi.org/10.1016 j.radonc.2019.06.024. ISSN 0167-8140.

[64] Gridley DS, Pecaut MJ, Mao XW, Wroe AJ, Luo-Owen X. Biological effects of passive versus active scanning proton beams on human lung epithelial cells. Technol Cancer Res Treat 2015;14(1):81-98. https://doi.org/10.7785/ tcrt.2012.500392. ISSN 1533-0346.

[65] Girdhani S, Abel E, Katsis A, Rodriquez A, Senapati S, KuVillanueva A, et al., Abstract LB-280: FLASH: A novel paradigm changing tumor irradiation platform that enhances therapeutic ratio by reducing normal tissue toxicity and activating immune pathways. Cancer Res 2019;79(13 Suppl) LB-280, doi: 10.1158/15387445.AM2019-LB-280.

[66] Papiez L, DesRosiers C, Moskvin V. Very High Energy Electrons (50-250 MeV) and Radiation Therapy. Technol Cancer Res Treat 2002;1(2):105-10. ISSN 15330346, doi: 10.1177/153303460200100202.

[69] van de Water S, Safai S, Schippers JM, Weber DC, Lomax AJ. Towards FLASH proton therapy: the impact of treatment planning and machine characteristics on achievable dose rates. Acta Oncol 2019;58(10):1463-9. ISSN 0284-186X, doi: 10.1080/0284186x.2019.1627416.

[67] van Marlen P, Dahele M, Folkerts M, Abel E, Slotman BJ, Verbakel WFAR. Bringing FLASH to the clinic: treatment planning considerations for ultrahigh dose-rate proton beams. Int J Radiat Oncol Biol Phys ISSN 0360-3016, doi: 10.1016/j.ijrobp.2019.11.011. 
[68] Yeboah C, Sandison GA, Moskvin V. Optimization of intensity-modulated very high energy (50-250 MeV) electron therapy. Phys Med Biol 2002;47(8): 1285-301. https://doi.org/10.1088/0031-9155/47/8/305. ISSN 1361-6560.

[70] Moskvin V, Salvat F, Stewart DK, DesRosiers CM. PENELOPE Monte Carlo engine for treatment planning in radiation therapy with Very High Energy Electrons (VHEE) of 150-250 MeV. In: IEEE nuclear science symposium \& medical imaging conference; 2010. p. 1961-6. https://doi.org/10.1109/NSSMIC.2010.5874117. ISSN 1082-3654.

[71] Lagzda A, Angal-Kalinin D, Jones J, Jones R, Kirkby K. Relative insensitivity to inhomogeneities on very high energy electron dose distributions. In: Proc. of international particle accelerator conference (IPAC'17), Copenhagen, Denmark, May, 2017, no. 8 in International Particle Accelerator Conference, JACoW, Geneva, Switzerland, ISBN 978-3-95450-182-3. p. 4791-4, doi: 10.18429/ JACoW-IPAC2017-THPVA139, 2017.

[72] Bazalova-Carter M, Qu B, Palma B, Hårdemark B, Hynning E, Jensen C, Maxim PG, Loo Jr BW. Treatment planning for radiotherapy with very highenergy electron beams and comparison of VHEE and VMAT plans. Med Phys 2015;42(5):2615-25. https://doi.org/10.1118/1.4918923. ISSN 0094-2405.

[73] Kokurewicz K, Brunetti E, Welsh GH, Wiggins SM, Boyd M, Sorensen A, Chalmers AJ, Schettino G, Subiel A, DesRosiers C, Jaroszynski DA. Focused very high-energy electron beams as a novel radiotherapy modality for producing highdose volumetric elements. Sci Rep 2019;9(1). https://doi.org/10.1038/s41598019-46630-w. 10837, ISSN 2045-2322.

[74] Maxim PG, Tantawi SG, Loo BW. PHASER: A platform for clinical translation of FLASH cancer radiotherapy. Radiother Oncol 2019;139:28-33. https://doi.org/ 10.1016/j.radonc.2019.05.005. ISSN 0167-8140.

[75] Gamba D, Corsini R, Curt S, Doebert S, Farabolini W, Mcmonagle G, Skowronski PK, Tecker F, Zeeshan S, Adli E, Lindstrøm CA, Ross A, Wroe LM. The CLEAR user facility at CERN. Nucl Instrum Methods Phys Res Sect A Accelerat Spectr Detect Assoc Equip 2018;909:480-3. https://doi.org/10.1016/j. nima.2017.11.080. ISSN 0168-9002.

[76] Delorme R, Marchand D, Vallerand C. The PRAE Multidisciplinary Project. Nucl Phys News 2019;29(1):32-5. https://doi.org/10.1080/10619127.2019.1571833. ISSN 1061-9127.

[77] Clarke JA, Angal-Kalinin D, Bliss N, Buckley R, Buckley S, Cash R, et al. CLARA conceptual design report, J Instrument 2014;9(05)T05001-T05001, ISSN 1748 0221. doi: 10.1088/1748-0221/9/05/T05001.

[78] Chiu C, Fomytskyi M, Grigsby F, Raischel F, Downer MC, Tajima T. Laser electron accelerators for radiation medicine: a feasibility study. Med Phys 2004;31(7): 2042-52. https://doi.org/10.1118/1.1739301. ISSN 0094-2405.

[79] Kainz KK, Hogstrom KR, Antolak JA, Almond PR, Bloch CD, Chiu C, Fomytskyi M, Raischel F, Downer M, Tajima T. Dose properties of a laser accelerated electron beam and prospects for clinical application. Med Phys 2004;31(7):2053-67. https://doi.org/10.1118/1.1690194. ISSN 0094-2405.

[80] Ledingham KWD, Bolton PR, Shikazono N, Ma C-MC. Towards laser driven hadron cancer radiotherapy: a review of progress. Appl Sci 2014;4(3):402-43. https://doi.org/10.3390/app4030402. ISSN 2076-3417.

[81] Macchi A, Borghesi M, Passoni M. Ion acceleration by superintense laser-plasma interaction. Rev Mod Phys 2013;85:751-93. https://doi.org/10.1103/ RevModPhys.85.751.

[82] Higginson A, Gray RJ, King M, Dance RJ, Williamson SDR, Butler NMH, Wilson R, Capdessus R, Armstrong C, Green JS, Hawkes SJ, Martin P, Wei WQ, Mirfayzi SR, Yuan XH, Kar S, Borghesi M, Clarke RJ, Neely D, McKenna P. Near-100 MeV protons via a laser-driven transparency-enhanced hybrid acceleration scheme. Nat Commun 2018;9(1):724. https://doi.org/10.1038/s41467-018-03063-9. ISSN 2041-1723.

[83] Wagner F, Deppert O, Brabetz C, Fiala P, Kleinschmidt A, Poth P, Schanz VA, Tebartz A, Zielbauer B, Roth M, Stöhlker T, Bagnoud V. Maximum Proton Energy above $85 \mathrm{MeV}$ from the Relativistic Interaction of Laser Pulses with Micrometer Thick $\mathrm{CH}_{2}$ Targets. PRL 2016;116(20):205002. https://doi.org/10.1103/ PhysRevLett.116.205002.

[84] Danson CN, Haefner C, Bromage J, Butcher T, Chanteloup J-CF, Chowdhury EA, Galvanauskas A, Gizzi LA, Hein J, Hillier DI, Hopps NW, Kato Y, Khazanov EA, Kodama R, Korn G, Li R, Li Y, Limpert J, Ma J, Nam CH, Neely D, Papadopoulos D, Penman RR, Qian L, Rocca JJ, Shaykin AA, Siders CW, Spindloe C, Szatmári S, Trines RMGM, Zhu J, Zhu P, Zuegel JD. Petawatt and exawatt class lasers worldwide. High Power Laser Sci Eng 2019;7(e54):e54 https://doi.org/10.1017/hpl.2019.36. ISSN 2095-4719.

[85] Margarone D, Cirrone GAP, Cuttone G, Amico A, Andó L, Borghesi M, et al. ELIMAIA: A laser-driven ion accelerator for multidisciplinary applications. Quant Beam Sci 2(2), ISSN 2412-382X. doi: 10.3390/qubs2020008.

[86] Scuderi V, Amato A, Amico AG, Borghesi M, Cirrone GAP, Cuttone G, et al. Diagnostics and dosimetry solutions for multidisciplinary applications at the ELIMAIA beamline. Appl Sci 8(9), ISSN 2076-3417, doi: 10.3390/app8091415.

[87] Romano F, Schillaci F, Cirrone GAP, Cuttone G, Scuderi V, Allegra L, et al. The ELIMED transport and dosimetry beamline for laser-driven ion beams. Nucl Instrum Methods Phys Res Sect A Accelerat Spectr Detect Assoc Equip 2016;829: 153-8. ISSN 0168-9002, doi: 10.1016/j.nima.2016.01.064.

[88] Richter C, Beyreuther E, Dammene Y, Enghardt W, Kaluza M, Karsch L, et al. SUGG-T-459: Laser-based particle acceleration for future ion therapy: current status of the joint project OnCOOPtics with special focus on beam delivery and dosimetry. Med Phys 2010;37(6Part23):3292-3292, ISSN 0094-2405, doi: 10.1118/1.3468857.

[89] Busold S, Almomani A, Bagnoud V, Barth W, Bedacht S, Blažević A, et al. Shaping laser accelerated ions for future applications - The LIGHT collaboration. Nuc
Instrum Methods Phys Res Sect A Accelerat Spectr Detect Assoc Equip 2014;740: 94-8, ISSN 0168-9002. doi: 10.1016/j.nima.2013.10.025.

[90] Jahn D, Schumacher D, Brabetz C, Ding J, Weih S, Kroll F, Brack FE, Schramm U, Blaževic A, Roth M. First application studies at the laser-driven LIGHT beamline: improving proton beam homogeneity and imaging of a solid target. Nucl Instrum Methods Phys Res Sect A Accelerat Spectr Detect Assoc Equip 2018;909:173-6. https://doi.org/10.1016/j.nima.2018.02.026. ISSN 0168-9002.

[91] Masood U, Cowan TE, Enghardt W, Hofmann KM, Karsch L, Kroll F, Schramm U, Wilkens JJ, Pawelke J. A light-weight compact proton gantry design with a novel dose delivery system for broad-energetic laser-accelerated beams. Phys Med Biol 2017;62(13):5531-55. https://doi.org/10.1088/1361-6560/aa7124. ISSN 13616560 .

[92] Lindner FH, Haffa D, Bin JH, Englbrecht F, Gao Y, Gebhard J, Hartmann J, Hilz P, Kreuzer C, Lehrack S, Ostermayr TM, Rösch TF, Speicher M, Würl M, Parodi K, Schreiber J, Thirolf PG. Towards swift ion bunch acceleration by high-power laser pulses at the Centre for Advanced Laser Applications (CALA). Nucl Instrum Methods Phys Res Sect B Beam Interactions Mater Atoms 2017;402:354-7. https://doi.org/10.1016/j.nimb.2017.02.088. ISSN 0168-583X.

[93] Toth C, Evans D, Gonsalves AJ, Kirkpatrick M, Magana A, Mannino G, et al. Transition of the BELLA PW laser system towards a collaborative research facility in laser plasma science. AIP Conf Proc 2017;1812(1):110005, ISSN 0094-243X, doi: 10.1063/1.4975918.

[94] Feist H, Muller U. Measurement of the total stopping power of $5.3 \mathrm{MeV}$ electrons in polystyrene by means of electron beam absorption in ferrous sulphate solution. Phys Med Biol 1989;34(12):1863-9, ISSN 1361-6560, URL: https://doi.org/ 10.1088/0031-9155/34/12/009.

[95] Vörös S, Anton M, Boillat B. Relative response of alanine dosemeters for highenergy electrons determined using a Fricke primary standard. Phys Med Biol 2012;57(5):1413-32. ISSN 1361-6560. URL: https://doi.org/10.1088/0031 9155/57/5/1413.

[96] Boag JW, Epp E, Fielden EM, Parker RP. ICRU Report 34: The Dosimetry of Pulsed Radiation, 3. Chemical Dosimetry, Reports of the International Commission on Radiation Units and Measurements os-18 1982;(1):14-21, ISSN 0579-5435, doi: 10.1093/jicru_os18.1.14, URL: https://journals.sagepub.com/doi/abs/10.1093/ jicru_os18.1.14.

[97] Sehested K, Bjergbakke E, Lang Rasmussen O, Fricke H. Reactions of $\mathrm{H} 2 \mathrm{O} 3$ in the pulse-irradiated Fe(II)-O2 system. J Chem Phys 1969;51(8):3159-66. https://doi. org/10.1063/1.1672489. ISSN 0021-9606.

[98] Thomas JK, Hart EJ. The radiolysis of aqueous solutions at high intensities. Radiat Res 1962;17(3):408-18. ISSN 00337587, 19385404. URL: www.jstor.org/stable/ 3571103

[99] McEwen MR, DuSautoy AR. Primary standards of absorbed dose for electron beams. METROLOGIA 2009;46(2):S59-79. https://doi.org/10.1088/0026-1394/ 46/2/S05. ISSN 0026-1394.

[100] Seuntjens J, Duane S. Photon absorbed dose standards. METROLOGIA 2009;46(2, SI):S39-58. https://doi.org/10.1088/0026-1394/46/2/S04. ISSN 0026-1394.

[101] Palmans H, Thomas R, Simon M, Duane S, Kacperek S, DuSautoy A, Verhaegen F. A small-body portable graphite calorimeter for dosimetry in low-energy clinical proton beams. Phys Med Biol 2004;49(16):3737-49, ISSN 0031-9155, doi: 10.1088/0031-9155/49/16/019, World Congress on Medical Physics and Biomedical Engineering, Sydney, AUSTRALIA, AUG 24-29, 2003.

[102] Rossomme S, Palmans H, Thomas R, Lee N, Duane S, Bailey M, Shipley D, Bertrand D, Romano F, Cirrone P, Cuttone G, Vynckier S. Reference dosimetry for light-ion beams based on graphite calorimetry. Radiat Protect Dosimetry 2014; 161(1-4):92-5. https://doi.org/10.1093/rpd/nct299. ISSN 0144-8420.

[103] Green S, Amos R, Van den Heuvel F, Kacperek A, MacKay RI, Palmans H, D'Souza D, Thomas R. IPEM Code of Practice for proton and ion beam dosimetry: update on work in progress. Radiother Oncol 2017;123(1):S783-4. https://doi. org/10.1016/S0167-8140(17)31902-3. ISSN 0167-8140.

[104] IAEA. Absorbed Dose Determination in External Beam Radiotherapy, no. 398 in Technical Reports Series, International atomic energy agency, Technical Reports Series No. 398, Vienna, ISBN 92-0-102200-X, URL:https://www.iaea.org/publica tions/5954/absorbed-dose-determination-in-external-beam-radiotherapy; 2006.

[105] Katsis A, Busold S, Mascia A, Heese J, Marshall A, Smith C, et al. Treatment Planning and Dose Monitoring for Small Animal Proton FLASH Irradiations. Med Phys 2019;46(6)E380, ISSN 0094-2405, Annual Meeting of the AmericanAssociation-of-Physicists-in-Medicine (AAPM), San Antonio, TX, JUL 14-18, 2019

[106] Richter C, Karsch L, Dammene Y, Kraft S, Metzkes J, Schramm U, Schrer M, Sobiella M, Weber A, Zeil K, Pawelke J. A dosimetric system for quantitative cell irradiation experiments with laser-accelerated protons. Phys Med Biol 2011;56 (6):1529-43. https://doi.org/10.1088/0031-9155/56/6/002. ISSN 00319155. URL:https://www.scopus.com/inward/record.uri?eid=2-s2.0-79952937485\&do $\mathrm{i}=10.1088 \% 2 \mathrm{f0031}-9155 \% 2 \mathrm{f} 56 \% 2 \mathrm{f} 6 \% 2 \mathrm{f00}$ \& $\mathrm{partnerID}=40 \& \mathrm{md} 5=\mathrm{ccc} 8 \mathrm{e} 90$ f8789f1573ca5a3cbf47e75a9.

[107] Fiorini F, Kirby D, Borghesi M, Doria D, Jeynes J, Kakolee K, Kar S, Kaur S, Kirby K, Merchant M, Green S. Dosimetry and spectral analysis of a radiobiological experiment using laser-driven proton beams. Phys Med Biol 2011; 56(21):6969-82. https://doi.org/10.1088/0031-9155/56/21/013. ISSN 00319155. URL:https://www.scopus.com/inward/record.uri? eid=2-s2.0-8005 $4809765 \&$ doi $=10.1088 \% 2$ f0031-9155\%2f56\%2f $21 \% 2$ f013\&partnerID $=40$ $\& m d 5=d 7 d f c 62 e d 1240559 f a 687 f 88 b 36 \mathrm{e} 2 \mathrm{a} 78$.

[108] Polin K, Doria D, Romagnani L, Chaudhary P, Cirrone G, Maiorino C, Milluzzo G, Petringa G, Romano F, Schettino G, Scuderi V, Prise K, Borghesi M. Irradiation and dosimetry arrangement for a radiobiological experiment employing laser- 
accelerated protons. J Instrum 2019;14(10):C10015. https://doi.org/10.1088/ 1748-0221/14/10/c10015.

[109] Bolton P, Borghesi M, Brenner C, Carroll D, De Martinis C, Fiorini F, Flacco A, Floquet V, Fuchs J, Gallegos P, Giove D, Green J, Green S, Jones B, Kirby D, McKenna P, Neely D, Nuesslin F, Prasad R, Reinhardt S, Roth M, Schramm U, Scott G, Ter-Avetisyan S, Tolley M, Turchetti G, Wilkens J. Instrumentation for diagnostics and control of laser-accelerated proton (ion) beams. Phys Med 2014 30(3):255-70. https://doi.org/10.1016/j.ejmp.2013.09.002. ISSN 11201797. URL:https://www.scopus.com/inward/record.uri?eid=2-s2.0-84896094375\&doi $=10.1016 \% 2 \mathrm{fj}$. ejmp.2013.09.002\&partnerID $=40 \& \mathrm{md} 5=267 \mathrm{f} 9 \mathrm{c} 2855 \mathrm{de} 44 \mathrm{cf} 23 \mathrm{c}$ 5fee05297dd18.

[110] Romano F, Subiel A, McManus M, Lee ND, Palmans H, Thomas R, et al. Challenge in dosimetry of particle beams with ultra-high pulse dose rates. J Phys; in-press.

[111] McManus M, Romano F, Lee ND, Farabolini W, Gilardi A, Royle G, et al. The challenge of ionisation chamber dosimetry in ultra-short pulsed high dose-rate Very High Energy Electron beams. Sci Rep 10(1), ISSN 2045-2322, doi: 10.1038/ s41598-020-65819-y.

[112] Boag JW. Ionization measurements at very high intensities-Part I. British J Radio 1950;23(274):601-11. https://doi.org/10.1259/0007-1285-23-274-601. URL: https://doi.org/10.1259/0007-1285-23-274-601, pMID: 14777875

[113] Boag JW, Hochhäuser E, Balk A. The effect of free-electron collection on the recombination correction to ionization measurements of pulsed radiation. Phys Med Biol 41, doi: 10.1088/0031-9155/41/5/005.

[114] Di Martino F, Giannelli M, Traino AC, Lazzeri M. Ion recombination correction for very high dose-per-pulse high-energy electron beams. Med Phys 2005;32(7Part1): 2204-10. https://doi.org/10.1118/1.1940167. ISSN 0094-2405.

[115] Bourgouin A, Cojocaru C, Ross C, McEwen M. Determination of Wair in highenergy electron beams using graphite detectors. Med Phys 2019;46(11): 5195-208. https://doi.org/10.1002/mp.13772. URL:https://aapm.onlinelibrary. wiley.com/doi/abs/10.1002/mp.13772.

[116] Jorge PG, Jaccard M, Petersson K, Gondré M, Durán MT, Desorgher L, Germond J F, Liger P, Vozenin M-C, Bourhis J, Bochud F, Moeckli R, Bailat C. Dosimetric and preparation procedures for irradiating biological models with pulsed electron beam at ultra-high dose-rate. Radiother Oncol 2019;139:34-9. https://doi.org/ 10.1016/j.radonc.2019.05.004. ISSN 0167-8140.

[117] Newhauser WD, Zhang R. The physics of proton therapy. Phys Med Biol 2015;60 (8):R155-209. ISSN 1361-6560. URL: https://doi.org/10.1088/0031-9155/60/ 8/R155.

[118] Palmans H, Thomas R, Kacperek A. Ion recombination correction in the Clatterbridge Centre of Oncology clinical proton beam. Phys Med Biol 2006;51 (4):903-17. ISSN 1361-6560. URL: https://doi.org/10.1088/0031-9155/51/4/ 010

[119] Gotz M, Karsch L, Pawelke J, A new model for volume recombination in planeparallel chambers in pulsed fields of high dose-per-pulse. Phys Med Biol 62(22), doi: 10.1088/1361-6560/aa8985.

[120] Hösl A, Häfliger P, Franck CM. Measurement of ionization, attachment detachment and charge transfer rate coefficients in dry air around the critical electric field. J Phys D Appl Phys 50(48), doi: 10.1088/1361-6463/aa8faa.

[121] Renaud J, Marchington D, Seuntjens J, Sarfehnia A. Development of a graphite probe calorimeter for absolute clinical dosimetry. Med Phys 2013;40(2):020701. https://doi.org/10.1118/1.4773870. URL:https://aapm.onlinelibrary.wiley. com/doi/abs/10.1118/1.4773870.

[122] Renaud J, Sarfehnia A, Bancheri J, Seuntjens J. Aerrow: A probe-format graphite calorimeter for absolute dosimetry of high-energy photon beams in the clinical environment. Med Phys 2018;45(1):414-28. https://doi.org/10.1002/mp.12669. ISSN 0094-2405. URL: https://doi.org/10.1002/mp.12669.

[123] Renaud J, Seuntjens J, Sarfehnia A. Sci-Sat AM: radiation dosimetry and practical therapy solutions - 03: Energy dependence of a clinical probe-format calorimeter and its pertinence to absolute photon and electron beam dosimetry. Med Phys 2016;43(8Part3):4959. https://doi.org/10.1118/1.4961857. ISSN 0094-2405 URL:https://doi.org/10.1118/1.4961857.

[124] Knoll GF. Radiation detection and measurement. 4th ed., New York, NY: Wiley. URL:https://cds.cern.ch/record/1300754, 2010.

[125] Van Dam J, Leunens G, Dutreix A. Correlation between temperature and dose rate dependence of semiconductor response; influence of accumulated dose. Radiothe Oncol 1990;19(4):345-51. ISSN 0167-8140. URL:http://www.sciencedirect.com. science/article/pii/016781409090035U.

[126] Grusell E, Rikner G. Linearity with dose rate of low resistivity p-type silicon semiconductor detectors. Phys Med Biol 1993:38(6):785-92. ISSN 1361-6560. URL: https://doi.org/10.1088/0031-9155/38/6/011.

[127] Grusell E, Medin J, Grusell E. General characteristics of the use of silicon diode detectors for clinical dosimetry in proton beams. Phys Med Biol 2000;45(9): 2573-82. ISSN 1361-6560. URL: https://doi.org/10.1088/0031-9155/45/9/310.

[128] Shi J, Simon WE, Zhu TC. Modeling the instantaneous dose rate dependence of radiation diode detectors. Med Phys 2003;30(9):2509-19. https://doi.org/ 10.1118/1.1602171. ISSN 0094-2405. URL: https://doi.org/10.1118/1.1602171.

[129] Saini AS, Zhu TC. Dose rate and SDD dependence of commercially available diode detectors. Med Phys 2004;31(4):914-24. https://doi.org/10.1118/1.1650563. ISSN 0094-2405. URL: https://doi.org/10.1118/1.1650563.

[130] Jursinic PA. Dependence of diode sensitivity on the pulse rate of delivered radiation. Med Phys 2013;40(2). https://doi.org/10.1118/1.4788763. 021720, ISSN 0094-2405. URL: https://doi.org/10.1118/1.4788763.

[131] Da Via C, Boscardin M, Dalla Betta G-F, Darbo G, Fleta C, Gemme C, Grenier P, Grinstein S, Hansen T-E, Hasi J, Kenney C, Kok A, Parker S, Pellegrini G, Vianello E, Zorzi N. 3D silicon sensors: design, large area production and quality assurance for the ATLAS IBL pixel detector upgrade. Nucl Instrum Methods Phys
Res Sect A Accelerat Spectr Detect Assoc Equip 2012;694:321-30. ISSN 01689002. URL:http://www.sciencedirect.com/science/article/pii/S016890021200 8509.

[132] Fleta C, Esteban S, Baselga M, Quirion D, Pellegrini G, Guardiola C, CortésGiraldo MA, López JG, Ramos MCJ, Gómez F, Lozano M. 3D cylindrical silicon microdosimeters: fabrication, simulation and charge collection study. J Instrum 2015;10(10):P10001. ISSN 1748-0221. URL: https://doi.org/10.1088/17480221/10/10/P10001.

[133] Prieto-Pena J, Gómez F, Fleta C, Guardiola C, Pellegrini G, Donetti M, Giordanengo S, González-Castaño DM, Pardo-Montero J. Microdosimetric spectra measurements on a clinical carbon beam at nominal therapeutic fluence rate with silicon cylindrical microdosimeters. IEEE Trans Nucl Sci 2019;66(7):1840-7. ISSN 1558-1578.

[134] Pimpinella M, Stravato A, Guerra AS, De Coste V, Marinelli M, Verona-Rinati G, Falco MD. Energy dependence of PTW microdiamond detector in radiotherapy photon and electron beams. Phys Med Eur J Med Phys 2014;30:e64. https://doi. org/10.1016/j.ejmp.2014.07.195. ISSN 1120-1797. URL: https://doi.org/ 10.1016/j.ejmp.2014.07.195

[135] Di Venanzio C, Marinelli M, Milani E, Prestopino G, Verona C, Verona-Rinati G, Falco MD, Bagalá P, Santoni R, Pimpinella M. Characterization of a synthetic single crystal diamond Schottky diode for radiotherapy electron beam dosimetry. Med Phys 2013;40(2). https://doi.org/10.1118/1.4774360. 021712, ISSN 00942405. URL: https://doi.org/10.1118/1.4774360.

[136] Bagalá P, Di Venanzio C, Falco MD, Guerra AS, Marinelli M, Milani E, Pimpinella M, Pompili F, Prestopino G, Santoni R, Tonnetti A, Verona C, VeronaRinati G. Radiotherapy electron beams collimated by small tubular applicators: characterization by silicon and diamond diodes. Phys Med Biol 2013;58(22): 8121-33. ISSN 1361-6560. URL: https://doi.org/10.1088/0031-9155/58/22/ 8121.

[137] Laub WU, Crilly R. Clinical radiation therapy measurements with a new commercial synthetic single crystal diamond detector. J Appl Clin Med Phys 2014;15(6):92-102. https://doi.org/10.1120/jacmp.v15i6.4890. ISSN 15269914. URL: https://doi.org/10.1120/jacmp.v15i6.4890.

[138] Pimpinella M, Ciancaglioni I, Consorti R, Venanzio CD, Guerra AS, Petrucci A, Stravato A, Verona-Rinati G. A synthetic diamond detector as transfer dosimeter for Dw measurements in photon beams with small field sizes. Metrologia 2012;49 (5):S207-10. ISSN 1681-7575. URL: https://doi.org/10.1088/0026-1394/49/5/ S207.

[139] Mandapaka AK, Ghebremedhin A, Patyal B, Marinelli M, Prestopino G, Verona C, Verona-Rinati G. Evaluation of the dosimetric properties of a synthetic single crystal diamond detector in high energy clinical proton beams. Med Phys 2013;40 (12). https://doi.org/10.1118/1.4828777. 121702, ISSN 0094-2405. URL: https://doi.org/10.1118/1.4828777.

[140] Marinelli M, Pompili F, Prestopino G, Verona C, Verona-Rinati G, Cirrone GAP, Cuttone G, La Rosa RM, Raffaele L, Romano F, Tuvé C. Dosimetric characterization of a synthetic single crystal diamond detector in a clinical $62 \mathrm{MeV}$ ocular therapy proton beam. Nucl Instrum Methods Phys Res Sect A Accelerat Spectr Detect Assoc Equip 2014;767:310-7. ISSN 0168-9002. URL:http://www sciencedirect.com/science/article/pii/S0168900214009966.

[141] Marsolat F, Marzi LD, Patriarca A, Nauraye C, Moignier C, Pomorski M, Moignau F, Heinrich S, Tromson D, Mazal A. Dosimetric characteristics of four PTW microDiamond detectors in high-energy proton beams. Phys Med Biol 2016; 61(17):6413-29. https://doi.org/10.1088/0031-9155/61/17/6413.

[142] Di Venanzio C, Marinelli M, Tonnetti A, Verona-Rinati G, Falco MD, Pimpinella M, Ciccotelli A, De Stefano S, Felici G, Marangoni F. Characterization of a microDiamond detector in high-dose-per-pulse electron beams for intra operative radiation therapy. Phys Med 2015;31(8):897-902. ISSN 1120-1797. URL:http://www.sciencedirect.com/science/article/pii/S1120179715001489.

[143] Poikela T, Plosila J, Westerlund T, Campbell M, Gaspari MD, Llopart X, Gromov V, Kluit R, van Beuzekom M, Zappon F, Zivkovic V, Brezina C, Desch K, Fu Y, Kruth A. Timepix3: a 65K channel hybrid pixel readout chip with simultaneous ToA/ToT and sparse readout. J Instrum 2014;9(05):C05013. https://doi.org/10.1088/1748-0221/9/05/c05013. URL: https://doi.org/ $10.1088 \% 2 \mathrm{~F} 1748-0221 \% 2 \mathrm{~F} 9 \% 2 \mathrm{~F} 05 \% 2 \mathrm{Fc} 05013$.

[144] Schüller A, Illemann J, Renner F, Makowski C, Kapsch R-P. Traceable charge measurement of the pulses of a $27 \mathrm{MeV}$ electron beam from a linear accelerator. J Instrum 2017;12(03):P03003. ISSN 1748-0221. URL: https://doi.org/10.1088/ 1748-0221/12/03/P03003.

[145] Courtois C, Boissonnat G, Brusasco C, Colin J, Cussol D, Fontbonne JM, Marchand B, Mertens T, de Neuter S, Peronnel J. Characterization and performances of a monitoring ionization chamber dedicated to IBA-universal irradiation head for Pencil Beam Scanning. Nucl Instrum Methods Phys Res Sect A Accelerat Spectr Detect Assoc Equip 2014;736:112-7. ISSN 0168-9002. URL: http://www.sciencedirect.com/science/article/pii/S0168900213013326.

[146] Boissonnat G, Fontbonne J-M, Balanzat E, Boumard F, Carniol B, Cassimi A, Colin J, Cussol D, Etasse D, Fontbonne C, Frelin A-M, Hommet J, Salvador S. Characterization and performances of DOSION, a dosimetry equipment dedicated to radiobiology experiments taking place at GANIL. Nucl Instrum Methods Phys Res Sect A Accelerat Spectr Detect Assoc Equip 2017;856:1-6. ISSN 0168-9002. URL:http://www.sciencedirect.com/science/article/pii/S0168900216313079.

[147] Busold S, Heese J. Proton beam diagnostics for ultra-high dose rate irradiations. PTCOG58, doi: 10.26226/morressier.5cb7218dae0a0900158305c6.

[148] Rühm W, Ainsbury E, Breustedt B, Caresana M, Gilvin P, Knezevic Z, Rabus H, Stolarczyk L, Vargas A, Bottollier-Depois J, Harrison R, Lopez M, Stadtmann H, Tanner R, Vanhavere F, Woda C, Clairand I, Fantuzzi E, Fattibene P, Hupe O, Olko P, Olšovcovä V, Schuhmacher H, Alves J, Miljanic S. The European radiation 
dosimetry group - review of recent scientific achievements. Radiat Phys Chem 2020;168. https://doi.org/10.1016/j.radphyschem.2019.108514. 108514, ISSN 0969-806X. URL:http://www.sciencedirect.com/science/article/pii/S0969806 X19310060.

[149] Ferrari A, Ferrarini M, Pelliccioni M. Secondary particle yields from 400MeV/u carbon ion and $250 \mathrm{MeV}$ proton beams incident on thick targets. Nucl Instrum Methods Phys Res Sect B Beam Interactions Mater Atoms 2011;269(13):1474-81. ISSN 0168-583X. URL:http://www.sciencedirect.com/science/article/pii/ S0168583X11003442.

[150] Caresana M, Ferrarini M, Manessi GP, Silari M, Varoli V. LUPIN, a new instrument for pulsed neutron fields. Nucl Instrum Methods Phys Res Sect A Accelerat Spectr Detect Assoc Equip 2013;712:15-26, ISSN 0168-9002. URL:http://www.scienc edirect.com/science/article/pii/S016890021300168X.

[151] Caresana M, Denker A, Esposito A, Ferrarini M, Golnik N, Hohmann E, Leuschner A, Luszik-Bhadra M, Manessi G, Mayer S, Ott K, Röhrich J, Silari M, Trompier F, Volnhals M, Wielunski M. Intercomparison of radiation protection instrumentation in a pulsed neutron field. Nucl Instrum Methods Phys Res Sect A Accelerat Spectr Detect Assoc Equip 2014;737:203-13. ISSN 0168-9002. URL: http://www.sciencedirect.com/science/article/pii/S0168900213016355.
[152] Caresana M, Cassell C, Ferrarini M, Hohmann E, Manessi GP, Mayer S, et al. A new version of the LUPIN detector: improvements and latest experimental verification. Rev Sci Instrum 2014;85(6):065102, ISSN 0034-6748, doi: 10.1063/ 1.4879936, URL: https://doi.org/10.1063/1.4879936.

[153] Cassell C, Ferrarini M, Rosenfeld A, Caresana M. A novel technique for compensation of space charge effects in the LUPIN-II detector. Nucl Instrum Methods Phys Res Sect A Accelerat Spectr Detect Assoc Equip 2015;804:113-7. ISSN 0168-9002. URL:http://www.sciencedirect.com/science/article/pii/S0 168900215011171.

[154] Thomas DJ, Alevra AV, Hunt JB, Schraube H. Experimental Determination of the Response of Four Bonner Sphere Sets to Thermal Neutrons. Radiat Prot Dosimetry 1994;54(1):25-31. ISSN 0144-8420. URL:https://doi.org/10.1093/oxfordj ournals.rpd.a082312.

[155] Roberts NJ, Boso A. Investigation of digital electronics for the NPL Bonner Sphere Spectrometer. Nucl Instrum Methods Phys Res Sect A Accelerat Spectr Detect Assoc Equip 2020;969:163959, ISSN 0168-9002. URL:http://www.sciencedirect. com/science/article/pii/S0168900220304290. 